\title{
Failure behavior of composite laminates under four-point bending
}

\author{
Murat Koc, Fazil O Sonmez, Nuri Ersoy and Kenan Cinar
}

\begin{abstract}
In this study, failure behavior of fiber-reinforced composites under four-point bending is investigated. First, the tests are modeled analytically using the classical lamination theory $(C L T)$. The maximum allowable moment resultants of $\left[\theta_{12}\right]_{T}$ offaxis laminate as well as balanced and symmetric angle-ply $\left[\theta_{3} /-\theta_{3}\right]_{s}$ composite laminates as a function of fiber orientation angle, $\theta$, are obtained using Tsai-Wu, maximum stress, maximum strain, Hashin, Tsai-Hill, Hoffman, quadric surfaces, modified quadric surfaces, and Norris failure criteria. Second, the same tests are simulated using the finite element method (FEM). Thermal residual stresses are calculated and accounted for in the failure analysis. An analysis is conducted for optimal positioning of the supports so as to ensure that intralaminar failure modes dominate interlaminar (delamination) failure mode. A test setup is then constructed accordingly and experiments are conducted. The correlation of the predicted failure loads and the experimental results is discussed. The quadric surfaces criterion is found to correlate better with the experimental results among the chosen failure criteria for the selected configurations.
\end{abstract}

\section{Keywords}

Laminated composites, failure criteria, residual stresses, out-of-plane loading, four-point bending, classical lamination theory, finite element modeling

\section{Introduction}

Composite materials are widely used because of their high stiffness-to-weight and strength-to-weight ratios. Composites can be tailored to achieve desired characteristics by changing their laminate configurations in the design stage. For the safe use of composite plates, one should use reliable failure theories during design stage that will correctly predict failure under given loading conditions for any chosen laminate configuration.

There are numerous failure criteria proposed to predict macroscale failure in composite structures in the literature. ${ }^{1-6}$ These failure criteria can be classified in several ways: the ones with or without stress interaction, stress or strain based, failure mode dependent or independent, linear or quadratic, physically based, i.e. based on failure mechanisms, etc.

Reliability of a failure criterion depends on its success in being able to accurately predict the failure for any different combinations of layup configuration, material, and loading condition. In many industrial applications, composite plates are subjected not to only in-plane loads but also out-of-plane loads. Recognizing that in-plane and out-of-plane responses of composite laminates can be quite different, ${ }^{7}$ a criterion validated for in-plane loading cannot be assumed to be also valid for out-of- plane loads. For this reason, there is a need to fully examine the validity of the failure criteria for out-ofplane loads. In this way, safety of a design can be ensured during a design process. Validity and reliability of composite failure criteria are well studied for in-plane loads. ${ }^{8-15}$ However, similar studies are quite limited in number for out-of-plane loads (i.e. bending moment, twisting moment, transverse force, or a combination of them), and the existing ones ${ }^{16-22}$ are not comprehensive; only some chosen configurations were studied under outof-plane loads: $\left[0_{8} / 90_{8}\right]_{\mathrm{s}}, \quad\left[90_{8} / 0_{8}\right]_{\mathrm{s}}, \quad\left[(0 / 90)_{8}\right]_{\mathrm{s}}, \quad[(45 / 0 /$ $\left.-45)_{5}\right]_{\mathrm{s}}, \quad\left[0_{18} /(90 /-90)\right]_{\mathrm{s}},{ }^{16}\left[( \pm 45 / 90 / 0)_{3}\right]_{\mathrm{s}},{ }^{17}\left[\left(0_{4} / 90_{4}\right)_{2}\right]_{\mathrm{s}}$, $\left[45_{3} / 0_{4} /-45_{3} / 90_{3}\right]_{\mathrm{s}},{ }^{18}\left[0_{14} /(22 /-22)_{3}\right]_{\mathrm{s}}, \quad\left[0_{16} /(39 /-39)_{2}\right]_{\mathrm{s}}$, $\left[0_{18} /(90 /-90)\right]_{\mathrm{s}},{ }^{19}\left[( \pm 45 / 90 / 0)_{3}\right]_{\mathrm{s}},{ }^{20}[5]_{8},[15]_{8},\left[5_{2} / 15_{4} / 5_{2}\right]$, $\left[15_{2} / 5_{4} / 15_{2}\right], \quad\left[15_{2} / 5_{2} / 15_{2} / 5_{2}\right], \quad\left[5_{2} / 15_{2} / 5_{2} / 15_{2}\right]{ }^{22}$ In these studies, usually three-point bending tests were performed. ${ }^{16,17,19-21}$ The disadvantage of this test setup is that the line force applied by the upper support causes

Department of Mechanical Engineering, Bogazici University, Istanbul, Bebek, Turkey

\section{Corresponding author:}

Fazil O Sonmez, Department of Mechanical Engineering, Bogazici University, Istanbul, Bebek 34342, Turkey.

Email: sonmezfa@boun.edu.tr 
non-uniform bending moment in the critical region of the plate. In that case, finite element results highly depend on mesh density. Besides, not only bending moment, but also transverse shear stress is induced; therefore, their separate effects cannot be differentiated. Three-point bending tests are normally used to measure shear strength of materials. Considering that the critical region is small, strength highly depends on the local density of micro defects in that region. Different distributions of defects in different specimens reduce the reliability of strength measurements. On the other hand, in four-point bending test specimens, predominantly bending moment develops between the loading locations. In the world-wide failure exercise (WWFE), Kaddour et al. ${ }^{13}$ compared the predictions of several criteria for $[+30 / 90 /-30 / 90]_{\mathrm{s}}$ glass/epoxy laminates under pure bending, but experimental correlation was not investigated. That study demonstrated that the predictions of the criteria exhibited a wide variation in strain values as well as in the initial location of damage. Kaddour and Hinton ${ }^{14,15}$ benchmarked failure theories for test cases in which hydrostatic pressure and shear loads were applied that induced triaxial stresses in the specimens.

For a failure theory, not only the accuracy of the predictions for some selected configurations, but also the accuracy of the predicted failure trend is important especially for design optimization studies. Typically, laminate configurations are optimized by varying fiber orientation angles of laminae. If a failure theory is used that incorrectly estimates the failure trend, i.e. increasing or decreasing trend of failure load with the change in the lamina angle, the optimization algorithm may converge on an inferior design. No experimental study exists on the failure trend for out-of-plane loads.

Because of the difference between the thermal expansion coefficients in the directions along and transverse to the fiber, residual stresses develop after laminae with different fiber orientations are joined at a high temperature and cooled down. Those macroscopic stresses may even cause matrix cracks during the cooling process before the application of mechanical loads. ${ }^{23}$ They may also lead to premature failure under loading.

In this study, the failure behavior of fiber-reinforced composites under out-of-plane loads is investigated. For this purpose, a four-point bending test setup is designed and constructed such that the intralaminar failure modes will be more critical than the delamination failure mode. $\left[\theta_{12}\right]_{\mathrm{T}}$ off-axis laminates and balanced and symmetric angle-ply $\left[\theta_{3} /-\theta_{3}\right]_{\mathrm{s}}$ composite laminates are tested. The experiments are repeated five times to obtain their strength. The tests are simulated using both the classical lamination theory (CLT) and the finite element method (FEM), and the maximum allowable moment resultants, $M_{\max }$, as a function of fiber orientation angle, $\theta$, are obtained using different failure criteria. For balanced and symmetric angle-ply laminates, the thermal residual stresses are taken into consideration in order to enhance the reliability of the analytical and numerical results. The values of $M_{\max }$ obtained numerically and analytically are then compared with the test results for specimens with $\left[\theta_{12}\right]_{\mathrm{T}}$ and $\left[\theta_{3} /-\theta_{3}\right]_{\mathrm{s}}$ layup sequences for fiber angles of $0^{\circ}$, $5^{\circ}, 15^{\circ}, 30^{\circ}, 45^{\circ}, 60^{\circ}, 75^{\circ}$, and $90^{\circ}$. In this way, not only the accuracy of the predictions is examined, but also the correlation of the predicted failure trend with the experimental results is checked.

\section{Analytical model of four-point bending test}

In order to apply the failure theories, the stress and strain states in the composite structure induced during testing need to be determined. These can be obtained via a structural analysis. For this purpose, both analytical and numerical methods are used in the present study.

The thickness of the specimens is small compared to their width and length (less than one-twentieth). In that case, the out-of-plane stress components can be assumed to be negligibly small $\left(\sigma_{z z}=\tau_{x z}=\tau_{y z}=0\right)$. Classical lamination theory (CLT) can then be utilized to relate the loading to the resulting stress and strain states. The loads on a laminate may be in-plane, $N_{x x}$, $N_{y y}, N_{x y}$, or out-of-plane, $M_{x x}, M_{y y}, M_{x y}$, as shown in Figure 1. Application of the loads creates strains that vary linearly through the thickness. In-plane strain state is expressed as ${ }^{24}$

$$
\left\{\begin{array}{l}
\varepsilon_{x x} \\
\varepsilon_{y y} \\
\gamma_{x y}
\end{array}\right\}=\left\{\begin{array}{c}
\varepsilon_{x x}^{0} \\
\varepsilon_{y y}^{0} \\
\gamma_{x y}^{0}
\end{array}\right\}+z\left\{\begin{array}{c}
\kappa_{x x} \\
\kappa_{y y} \\
\kappa_{x y}
\end{array}\right\}
$$

where $\varepsilon_{x x}^{o}, \varepsilon_{y y}^{o}$, and $\gamma_{x y}^{o}$ are the overall mid-plane strains and $\kappa_{x x}, \kappa_{y y}$, and $\kappa_{x y}$ are the overall curvature terms, respectively. The stress components are related to the

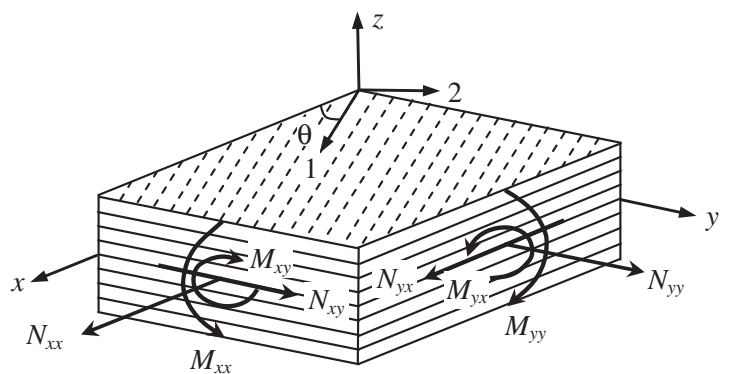

Figure I. A schematic of the composite laminate and the general loading conditions. ${ }^{7}$ 
strain components as

$$
\left\{\begin{array}{l}
\sigma_{x x} \\
\sigma_{y y} \\
\tau_{x y}
\end{array}\right\}_{k}=\left[\begin{array}{lll}
\bar{Q}_{11} & \bar{Q}_{12} & \bar{Q}_{16} \\
\bar{Q}_{12} & \bar{Q}_{22} & \bar{Q}_{26} \\
\bar{Q}_{16} & \bar{Q}_{26} & \bar{Q}_{66}
\end{array}\right]_{k}\left(\left\{\begin{array}{c}
\varepsilon_{x x} \\
\varepsilon_{y y} \\
\gamma_{x y}
\end{array}\right\}_{k}-\left\{\begin{array}{c}
\varepsilon_{x x}^{T} \\
\varepsilon_{y y}^{T} \\
\gamma_{x y}^{T}
\end{array}\right\}_{k}\right)
$$

where $k$ is the lamina number counted from the bottom, $\bar{Q}_{i j}$ are the components of the reduced stiffness matrix, which depend on the fiber orientation, $\theta_{k}$, and elastic properties of the material along the principal material directions, $E_{1}, E_{2}, G_{12}, v_{12}$, and $v_{21}{ }^{24}$ and $\varepsilon_{x x}^{T}, \varepsilon_{y y}^{T}, \gamma_{x y}^{T}$ are the thermal strains given by $\alpha_{x x} \Delta T, \alpha_{y y} \Delta T$, and $\alpha_{x y} \Delta T . \Delta T$ is the temperature difference between the cure temperature and the room temperature and $\alpha_{x x}$, $\alpha_{y y}$, and $\alpha_{x y}$ are the thermal expansion coefficients in the global $x$-direction, $y$-direction, and $x-y$ plane, respectively.

Stress resultants (forces and bending moments per unit lateral length of a cross section) are obtained by throughthe-thickness integration of the stresses in each ply as ${ }^{24}$

$$
\begin{aligned}
& \left\{\begin{array}{l}
N_{x x} \\
N_{y y} \\
N_{x y}
\end{array}\right\}=\int_{-h / 2}^{h / 2}\left\{\begin{array}{l}
\sigma_{x x} \\
\sigma_{y y} \\
\tau_{x y}
\end{array}\right\} \mathrm{d} z=\sum_{k=1}^{2 m} \int_{z_{k-1}}^{z_{k}}\left\{\begin{array}{c}
\sigma_{x x} \\
\sigma_{y y} \\
\tau_{x y}
\end{array}\right\}_{k} \mathrm{~d} z \\
& \left\{\begin{array}{l}
M_{x x} \\
M_{y y} \\
M_{x y}
\end{array}\right\}=\int_{-h / 2}^{h / 2}\left\{\begin{array}{c}
\sigma_{x x} \\
\sigma_{y y} \\
\tau_{x y}
\end{array}\right\} z \mathrm{~d} z=\sum_{k=1}^{2 m} \int_{z_{k-1}}^{z_{k}}\left\{\begin{array}{c}
\sigma_{x x} \\
\sigma_{y y} \\
\tau_{x y}
\end{array}\right\}_{k} z \mathrm{~d} z
\end{aligned}
$$

Here $m$ is the number of distinct laminae in one of the symmetric portions above or below the mid-plane. Substituting equation (1) into equation (2), which is in turn substituted into equations (3) and (4), one can obtain

$$
\begin{aligned}
\left\{\begin{array}{c}
N_{x x}+N_{x x}^{T} \\
N_{y y}+N_{y y}^{T} \\
N_{x y}+N_{x y}^{T} \\
M_{x x}+M_{x x}^{T} \\
M_{y y}+M_{y y}^{T} \\
M_{x y}+M_{x y}^{T}
\end{array}\right\}= & {\left[\begin{array}{llllll}
A_{11} & A_{12} & A_{16} & B_{11} & B_{12} & B_{16} \\
A_{12} & A_{22} & A_{26} & B_{12} & B_{22} & B_{26} \\
A_{16} & A_{26} & A_{66} & B_{16} & B_{26} & B_{66} \\
B_{11} & B_{12} & B_{16} & D_{11} & D_{12} & D_{16} \\
B_{12} & B_{22} & B_{26} & D_{12} & D_{22} & D_{26} \\
B_{16} & B_{26} & B_{66} & D_{16} & D_{26} & D_{66}
\end{array}\right] } \\
& \times\left\{\begin{array}{c}
\varepsilon_{x x}^{0} \\
\varepsilon_{y y}^{0} \\
\gamma_{x y}^{0} \\
\kappa_{x x} \\
\kappa_{y y} \\
\kappa_{x y}
\end{array}\right\}
\end{aligned}
$$

where $A_{i j}$ is membrane stiffness component, $D_{i j}$ is the bending stiffness component, and $B_{i j}$ are bendingextension coupling stiffness components. The expressions for $A_{i j}, B_{i j}$, and $D_{i j}$ and the solution of equation (5) can be found in Hyer et al. ${ }^{25}$ If a laminate is multidirectional, thermal force and moment resultants should also be taken into account in the failure analyses. They are calculated as

$$
\left\{\begin{array}{c}
N_{x x}^{T} \\
N_{y y}^{T} \\
N_{x y}^{T}
\end{array}\right\}=\sum_{k=1}^{2 m}\left[\begin{array}{lll}
\bar{Q}_{11} & \bar{Q}_{12} & \bar{Q}_{16} \\
\bar{Q}_{12} & \bar{Q}_{22} & \bar{Q}_{26} \\
\bar{Q}_{16} & \bar{Q}_{26} & \bar{Q}_{66}
\end{array}\right]_{k}\left\{\begin{array}{l}
\alpha_{x x} \\
\alpha_{y y} \\
\alpha_{x y}
\end{array}\right\}\left(z_{k}-z_{k-1}\right) \Delta T
$$

$\left\{\begin{array}{l}M_{x x}^{T} \\ M_{y y}^{T} \\ M_{x y}^{T}\end{array}\right\}=\sum_{k=1}^{2 m}\left[\begin{array}{lll}\bar{Q}_{11} & \bar{Q}_{12} & \bar{Q}_{16} \\ \bar{Q}_{12} & \bar{Q}_{22} & \bar{Q}_{26} \\ \bar{Q}_{16} & \bar{Q}_{26} & \bar{Q}_{66}\end{array}\right]_{k}\left\{\begin{array}{c}\alpha_{x x} \\ \alpha_{y y} \\ \alpha_{x y}\end{array}\right\}\left(z_{k}^{2}-z_{k-1}^{2}\right) \Delta T$.

Only symmetric laminates are considered in this study; then, the bending-extension coupling matrix terms, $B_{i j}$, (equation (5)) reduce to zero. Because of symmetry, thermal bending resultants, $M_{x x}^{T}, M_{y y}^{T}$, and, $M_{x y}^{T}$, are obtained to be zero from equation (5). Considering that the bars of the four-point bending test fixture prevent twisting of the composite plate specimen at four locations, the twisting curvature, $\kappa_{x y}$, is taken as zero. Then the corresponding twisting moment, $M_{x y}$, applied by the bars is unknown. The bending moment resultant $M_{y y}$ is taken as zero. The bending moment on the $x$-plane, $M_{x x}$, has such a magnitude that it makes the failure index equal to zero; in other words, it causes initial failure in the laminate. The fixture does not apply in-plane loads; hence, $N_{x x}, N_{y y}$, and $N_{x y}$ are equal to zero. Solving equation (5), the six unknown terms are obtained, $\varepsilon_{x x}^{o}, \varepsilon_{y y}^{o}, \gamma_{x y}^{o}, \kappa_{x x}, \kappa_{y y}$, and $M_{x y}$. Substituting them into equation (1), strain components with respect to global coordinates, $\varepsilon_{x x}, \varepsilon_{y y}$, and $\varepsilon_{x y}$ are obtained. From equation (2), stress components at each lamina, $\sigma_{x x}, \sigma_{y y}$, and $\tau_{x y}$, are determined. Using tensor transformation rules, strain and stress components in the principal material coordinates, $\varepsilon_{11}, \varepsilon_{22}, \varepsilon_{12}$ and $\sigma_{11}$, $\sigma_{22}, \tau_{12}$, respectively, can be obtained. Based on this information, failure analyses can be carried out.

\section{Intralaminar failure criteria for laminated composites}

In this study, some of the most widely recognized composite failure criteria with different characteristics are studied and their predictions are compared with the results of four-point bending tests, where the middle regions of the laminate are predominantly subjected to unidirectional bending moment. These criteria are 
Tsai-Wu, maximum stress, maximum strain, Hashin, Tsai-Hill, Hoffman, quadric surfaces, modified quadric surfaces, and Norris. In order to apply these criteria, the material strength data in principal material directions are needed; that means tensile and compressive strengths along the fibers, $X_{t}$ and $X_{c}$, and transverse to them, $Y_{t}$ and $Y_{c}$, respectively, and shear strength, $S_{12}$ are needed. These are readily available properties for most of the composite materials. There are numerous failure criteria proposed in the literature other than the ones selected in the present study. The failure criteria requiring different strength data obtained through special experimental setups such as $\mathrm{LARC} 03^{26}$ are not considered in the present study. The ones based on micromechanics and progressive failure models are also not considered. Benchmarking these criteria against the four-point bending tests is left as a future study.

Tsai-Wu failure criterion ${ }^{1}$ is a non-linear stressbased criterion which accounts for stress interaction; however, it does not predict failure mode. According to this criterion, the failure is predicted under plane stress state as ${ }^{24}$

$$
\begin{aligned}
& \frac{\sigma_{11}^{2}}{X_{t}\left|X_{c}\right|}-\frac{\sigma_{11} \sigma_{22}}{\sqrt{X_{t} X_{c} Y_{t} Y_{c}}}+\frac{\sigma_{22}^{2}}{Y_{t}\left|Y_{c}\right|}+\left(\frac{1}{X_{t}}+\frac{1}{X_{c}}\right) \sigma_{11} \\
& \quad+\left(\frac{1}{Y_{t}}+\frac{1}{Y_{c}}\right) \sigma_{22}+\frac{\tau_{12}^{2}}{S_{12}^{2}} \geq 1 .
\end{aligned}
$$

The maximum allowable moment resultant, $M_{\max }$, is the magnitude of $M_{x x}$ that makes the left hand side equal to 1.0 .

Tsai-Hill is a stress-based, quadratic, failure mode independent criterion accounting for stress interaction. According to the criterion, failure occurs if equation (9) is satisfied ${ }^{24}$

$$
\left(\frac{\sigma_{11}}{X}\right)^{2}-\frac{\sigma_{11} \sigma_{22}}{X^{2}}+\left(\frac{\sigma_{22}}{Y}\right)^{2}+\left(\frac{\tau_{12}}{S_{12}}\right)^{2} \geq 1
$$

wherein $X$ and $Y$ are either tensile or compression strength depending on the sign of the respective stresses.

Hoffman criterion ${ }^{2}$ is a stress-based, quadratic, failure mode independent criterion which accounts for stress interaction. This criterion is stated as

$$
\begin{aligned}
& \frac{\sigma_{11}^{2}}{X_{t}\left|X_{c}\right|}+\frac{\sigma_{11} \sigma_{22}}{X_{t} X_{c}}+\frac{\sigma_{22}^{2}}{Y_{t}\left|Y_{c}\right|}+\left(\frac{1}{X_{t}}+\frac{1}{X_{c}}\right) \sigma_{11} \\
& \quad+\left(\frac{1}{Y_{t}}+\frac{1}{Y_{c}}\right) \sigma_{22}+\frac{\tau_{12}^{2}}{S_{12}^{2}} \geq 1
\end{aligned}
$$

The quadric surfaces criterion ${ }^{3}$ is a stress-based, nonlinear, failure mode independent failure criterion with stress interaction. This criterion states that failure occurs if the following equation is satisfied

$$
\begin{gathered}
\frac{a}{X^{2}} \sigma_{11}^{2}+\frac{a}{Y^{2}} \sigma_{22}^{2}+\frac{a}{S_{12}^{2}} \tau_{12}^{2}+\frac{b}{X Y} \sigma_{11} \sigma_{22}+\frac{b}{X S_{12}} \sigma_{11} \tau_{12} \\
+\frac{b}{Y S_{12}} \sigma_{22} \tau_{12}+\frac{c}{X} \sigma_{11}+\frac{c}{Y} \sigma_{22}+\frac{c}{S_{12}} \tau_{12} \geq 1
\end{gathered}
$$

where $a=0.98, b=0.49$, and $c=0.002,{ }^{3}$ which are found by employing stability conditions and enforcing satisfaction of the equation for special loading cases like $a+c=1$ for $\sigma_{11}=X, \sigma_{22}=\tau_{12}=0$.

The modified quadric surfaces ${ }^{4}$ is a modification of the quadric surfaces criterion. The difference between them is that the coefficients of in-plane and shear coupling terms are assumed to be zero in the latter one. Accordingly, the equation becomes

$$
\begin{gathered}
\frac{a}{X^{2}} \sigma_{11}^{2}+\frac{a}{Y^{2}} \sigma_{22}^{2}+\frac{a}{S_{12}^{2}} \tau_{12}^{2}+\frac{b}{X Y} \sigma_{11} \sigma_{22} \\
+\frac{c}{X} \sigma_{11}+\frac{c}{Y} \sigma_{22}+\frac{c}{S_{12}} \tau_{12} \geq 1
\end{gathered}
$$

Norris $^{5}$ proposed a failure theory for orthotropic materials based on the Hencky-von Mises energy theory. It is a non-linear, stress-based criterion. The criterion accounts for stress interaction. According to Norris, the onset of failure occurs if at least one of the following equations is satisfied ${ }^{5}$

$$
\begin{aligned}
& \left(\frac{\sigma_{11}}{X}\right)^{2}+\left(\frac{\sigma_{22}}{Y}\right)^{2}-\frac{\sigma_{11} \sigma_{22}}{X Y}+\left(\frac{\tau_{12}}{S_{12}}\right)^{2} \geq 1 \\
& \text { or }\left(\frac{\sigma_{11}}{X}\right)^{2} \geq 1 \\
& \text { or }\left(\frac{\sigma_{22}}{Y}\right)^{2} \geq 1 .
\end{aligned}
$$

The maximum stress criterion is a linear, stress-based, failure mode dependent criterion without stress interaction. This criterion claims that failure occurs if one of the following conditions is satisfied ${ }^{24}$

$$
\begin{gathered}
X_{t} \leq \sigma_{11} \text { or } \sigma_{11} \leq X_{c} \\
Y_{t} \leq \sigma_{22} \text { or } \sigma_{22} \leq Y_{c} \\
\text { or }\left|\tau_{12}\right| \geq S_{12} .
\end{gathered}
$$

The maximum strain criterion is linear, strain based, and failure mode dependent; yet, it does not account for interaction between strains. According to this criterion, failure occurs if ${ }^{24}$

$$
\begin{aligned}
& \varepsilon_{11} \leq X_{\varepsilon_{c}} \text { or } X_{\varepsilon_{t}} \leq \varepsilon_{11} \\
& \varepsilon_{22} \leq Y_{\varepsilon_{c}} \text { or } Y_{\varepsilon_{t}} \leq \varepsilon_{22}
\end{aligned}
$$




$$
\text { or } S_{\varepsilon} \leq\left|\varepsilon_{12}\right|
$$

where $\mathrm{X}_{\varepsilon_{t}}, X_{\varepsilon_{c}}, Y_{\varepsilon_{t}}$, and $Y_{\varepsilon_{c}}$ are the maximum allowable tensile and compressive strains in the 1 and 2 directions (Figure 1), respectively, $\mathrm{S}_{\varepsilon}$ is the maximum shear strain in the 1-2 plane.

Hashin's criterion ${ }^{6}$ is a nonlinear and physically based failure criterion, which can predict the failure mode. It also accounts for stress interaction. According to the criterion, failure occurs under plane stress condition, if one of the following conditions occurs

$$
\begin{gathered}
\frac{\sigma_{11}^{2}}{X_{t}^{2}}+\frac{\tau_{12}^{2}}{S_{12}^{2}} \geq 1 \text { if } \sigma_{11}>0 \\
\frac{\sigma_{11}}{X_{c}} \geq 1 \text { if } \sigma_{11}<0 \\
\frac{\sigma_{22}^{2}}{Y_{t}^{2}}+\frac{\tau_{12}^{2}}{S_{12}^{2}} \geq 1 \text { if } \sigma_{22}>0 \\
\left(\frac{\sigma_{22}}{2 S_{23}}\right)^{2}+\left[\left(\frac{Y_{c}}{2 S_{23}}\right)^{2}-1\right] \frac{\sigma_{22}}{Y_{c}}+\left(\frac{\tau_{12}}{S_{12}}\right)^{2} \geq 1 \\
\text { if } \sigma_{22}<0
\end{gathered}
$$

where $\mathrm{S}_{23}$ is the maximum out-of-plane allowable shear stress in 2-3 plane.

\section{Finite element modeling of four-point bending test}

Finite element analysis of the plate is performed using commercial software ANSYS. SOLID185, a layered 3-D structural solid element, is used to generate mesh in the structural volume. SOLID185 is defined by eight nodes having three-degrees of freedom at each node; translations in the $x, y$, and $z$ directions. ${ }^{27}$ First, a finite element modeling of the test is developed. Second, a convergence analysis is carried out. Third, an analysis is conducted for optimal positioning of the loads so as to ensure that the intralaminar failure modes dominate over the delamination failure mode. For this purpose, the results of a delamination criterion $^{28}$ are compared with the results of Tsai-Wu and maximum stress failure criteria for different loading positions. Then, simulations are conducted using the optimal loading condition in which the most likely failure mode is intralaminar failure, not delamination. Lastly, all of the criteria are implemented into ANSYS, and $M_{\max }$ predictions are obtained as a function of fiber orientation angle.

The specimen and the loading conditions are modeled, failure criteria are applied and the maximum allowable moment resultants, $M_{\max }$, are found using ANSYS Parametric Design Language (APDL). $M_{\max }$ values are computed for fiber orientation angles, $\theta$, from $0^{\circ}$ to $90^{\circ}$ with $1^{\circ}$ increments.

First, 3-D model of the plate is built, fiber orientation angle is defined, and mesh is generated. Then, boundary conditions are defined. The nodes which coincide with bottom supports are held in the transverse, or $z$, direction. Tests are conducted under displacement control. In order to simulate the real test conditions, a displacement is defined for the nodes located at the position of the top supports. In order to account for thermal loads and calculate the resulting residual stresses, a thermal loading step prior to the mechanical loading step is included in the finite element analysis by introducing $\Delta T$ (temperature difference between the cure temperature and the room temperature) to the FE model. This thermal step simulates cooling of the laminate from the process temperature $\left(180^{\circ} \mathrm{C}\right)$ to the room temperature $\left(25^{\circ} \mathrm{C}\right)$ and calculates ply-level residual stresses due to mismatch between the coefficients of thermal expansion in the fiber and transverse directions; thus the magnitude of the residual stresses is independent of the mechanical loading conditions. After solution, stress and strain components at each node are obtained and failure analysis is carried out using the selected criteria. The analytical model based on CLT provides 2D-stress and strain states within the plate. In order to obtain the failure loads based on this information, 2D definitions of the failure criteria given by equations (8) to (21) are used. The FE model provides $3 \mathrm{D}$-stress and strain states within the plate. Accordingly, 3D definitions of the criteria are used to calculate the failure loads. Definitions of Tsai-Wu, maximum stress, maximum strain and Hashin failure criteria come as default in ANSYS; however, Tsai-Hill, Hoffman, quadric surfaces, modified quadric surfaces, and Norris criteria are implemented to the software using the parametric design language. The results of the nodes around the support locations are excluded in the failure analysis, because concentrated loads defined at the nodes cause stress concentration much severer than the actual case.

The objective is to determine the loading, in this case downward displacement of the upper support, such that the maximum failure index becomes equal to 1.0. This is found iteratively after successive solutions using secant method. Then the reaction force at a support, $F$, is obtained utilizing post-processing commands. Using the value of $F$ at the time of failure and the distance between the upper and lower supports, $a$, the maximum allowable moment resultant, $M_{\max }$, is calculated by $M_{\max }=F_{\max } a$.

The accuracy of the results of a finite element analysis depends on mesh density. Finer meshes, in general, 
increase the accuracy of the results. However, in some cases, model may contain singularity points, e.g. regions where concentrated forces exist. A concentrated force is considered to be applied on a region with zero area. A high mesh density around concentrated loads may result in unrealistically high stress levels. Besides that, computational cost may increase remarkably. Optimum mesh density should be determined before FE analyses are carried out.

Convergence analysis is performed for the middle regions, where predominantly bending moment develops. Tension and compression stresses occur due to bending moment below and above the mid-plane, respectively. Therefore, the maximum failure index at the top and the bottom, where the maximum stress develops, is considered in the convergence analysis.

Finite element models are developed for a 12-layered $48 \times 96 \times 2.208\left(\mathrm{~mm}^{3}\right)$ composite plate using different element sizes by dividing the length, width, and thickness for different numbers of divisions. The maximum failure index is computed using Tsai-Wu and maximum stress failure criteria and modified Hashin delamination criterion ${ }^{28}$ for each case. The delamination criterion is implemented into the software using the user programmable features of ANSYS. ${ }^{27}$ Based on the results, the size of a finite element is chosen as $1.0 \mathrm{~mm}$ along the length and width of the plate. The thickness of the elements is chosen the same as the thickness of a ply, which is $0.184 \mathrm{~mm}$.

\section{Test-setup design}

The setup is schematically depicted in Figure 2. In this part of the study, the optimum support positions are sought to minimize the likelihood of delamination. While the bottom supports are kept at the same position (at the right and left edges of the plate), different locations for the top supports are tried. The distance between the top supports and the nearest edges is changed from 14 to $32 \mathrm{~mm}$ with 2-mm increments for every $15^{\circ}$ of fiber orientation angle, $\theta$, from $0^{\circ}$ to $90^{\circ}$; delamination as well as intralaminar failure analyses are repeated for each configuration in order to find the

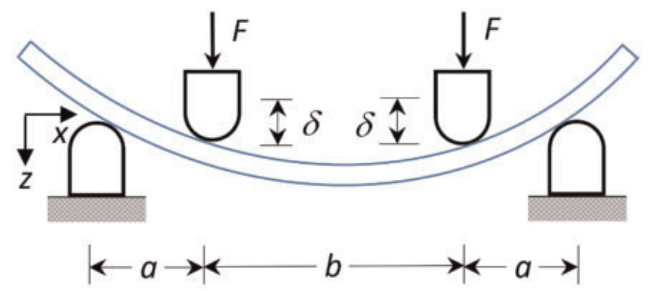

Figure 2. Schematic of the four-point bending test. setup design for which delamination risk is minimum. The delamination criterion ${ }^{28}$ is formulated as follows.

Delamination in tension $\left(\sigma_{33}>0\right)$

$$
\frac{\sigma_{33}^{2}}{Z_{t}^{2}}+\frac{\tau_{13}^{2}}{S_{13}^{2}}+\frac{\tau_{23}^{2}}{S_{23}^{2}} \geq 1
$$

Delamination in compression $\left(\sigma_{33}<0\right)$

$$
\frac{\sigma_{33}^{2}}{Z_{c}^{2}}+\frac{\tau_{13}^{2}}{S_{13}^{2}}+\frac{\tau_{23}^{2}}{S_{23}^{2}} \geq 1
$$

where $Z$ denotes strength in the three directions and $S_{13}$ and $\mathrm{S}_{23}$ refer to out-of-plane shear strengths. The finite element analyses are repeated for both unidirectional and multidirectional laminates and the load that causes initiation of delamination and the load that causes first-ply intralaminar failure are found for each configuration. Delamination is found not to be the dominant failure mode for unidirectional laminates. However, there is a risk of delamination for angle-ply plates with fiber angles between $30^{\circ}$ and $45^{\circ}$. According to the maximum stress criterion stated in equation (14), intralaminar failure is less critical than delamination for all support locations for angle-ply laminates with $30^{\circ}$ and $45^{\circ}$ fiber orientation angles. On the other hand, according to Tsai-Wu criterion, delamination can be avoided if the distance between the top supports and the nearest bottom support ( $a$ in Figure 2) is less than or equal to $20 \mathrm{~mm}$. The risk of delamination becomes smaller as the distance between the upper and lower supports is reduced. The magnitude of bending moment depends not only on the force ( $F$ in Figure 2 ) but also on the distance between the top and bottom supports, $a\left(M_{\max }=F a\right)$. If a very small distance is chosen, very high loads need to be applied by the test machine. Hence, the top supports are placed such that the distance between them, $b$, is $56 \mathrm{~mm}$ and the distance between them and the nearest lower support, $a$, is $20 \mathrm{~mm}$ in the finite element model as well as in the experiments.

\section{Experiments}

Experimental study is conducted in two stages: manufacturing of composite plates and four-point bending tests.

The plates are manufactured by stacking individual AS4/8552 unidirectional prepregs, a carbon-fiber-reinforced epoxy, in a $118 \times 190\left(\mathrm{~mm}^{2}\right)$ mold with desired stacking sequence and cured in a hot press in accordance with the manufacturer's recommended cure cycle. $^{29}$ Two or three specimens with $48 \mathrm{~mm}$ width and 115 or $135 \mathrm{~mm}$ length are cut from each plate. The samples are cut from at least two different plates 
by means of a diamond disk to prevent consistent error due to a potential manufacturing defect in a laminate. The prepreg's thickness and the fiber volume fraction (FVF) were reported to be $0.184 \mathrm{~mm}$ and $57.42 \%{ }^{29}$, respectively. Accordingly, 12-ply laminate would have $2.208 \mathrm{~mm}$ thickness. Thickness of each specimen is measured; their thickness is found to be $2.204 \mathrm{~mm}$ on average with a standard deviation of $0.018 \mathrm{~mm}$. In the structural analyses, the reported value, $2.208 \mathrm{~mm}$, is used.

The test setup, which is designed with the help of FE analyses, is manufactured from forged steel. The supports are made of silver steel.

Quasi-static tests are carried out under a monotonic loading with a constant displacement rate of $1.0 \mathrm{~mm} / \mathrm{min}$. The deflections of the specimens are measured from the downward movement of the upper supports, namely from the crosshead displacement of the test machine. The stiffness of the machine and the fixtures are not taken into account. Displacement of the upper supports, $\delta$, and the applied force, $2 F$, are recorded.

For each $15^{\circ}$ of fiber orientation angle, $\theta$, from $0^{\circ}$ to $90^{\circ}$, five specimens are tested. Some of the chosen failure criteria predict a slight increase in strength as the fiber angle is varied from 0 to $3-5^{\circ}$. For this reason, $\left[5_{12}\right]_{\mathrm{T}}$ and $\left[5_{3} /-5_{3}\right]_{\mathrm{s}}$ plates are additionally tested to observe the correlation between the experimental results and the predictions.

\section{Results and discussion}

\section{Material properties}

Mechanical properties of AS4/8552 are taken from the catalogue provided by Hexcel ${ }^{\circledR}{ }^{29}$ The stiffness of the material is slightly different under tension and compression. Taking different elastic properties under tension and compression complicates calculations significantly. Four-point bending induces tensile stresses below the mid-plane and compressive stresses above. However, different mechanical moduli under tension and compression disturb the symmetry condition even if the laminate has a symmetric stacking sequence. In that case, the coupling terms ( $B$ matrix) do not disappear. Considering that the differences in the stiffness properties under tension and compression is less than $5 \%$ in all cases, averaged values are used in this study. The properties missing in the catalogue like Poisson's ratios are taken from Lopes et al. ${ }^{30}$ Tables 1 and 2 present the material properties used in the analytical and FE models. Because laminae are transversely isotropic, one may assume the following equalities to hold: $Z_{t}=Y_{t}, Z_{c}=Y_{c}, S_{13}=S_{12}, v_{13}=v_{12}$, and $G_{23}=E_{2} / 2\left(1+v_{23}\right)$.
Table I. Mechanical properties of AS4/8552. ${ }^{29,30}$

\begin{tabular}{|c|c|c|c|c|c|c|}
\hline $\begin{array}{l}E_{1} \\
(\mathrm{GPa})\end{array}$ & $\begin{array}{l}E_{2} \\
(\mathrm{GPa})\end{array}$ & $\begin{array}{l}G_{12} \\
(\mathrm{GPa})\end{array}$ & $v_{12}$ & $v_{23}$ & $\begin{array}{l}\alpha_{1} \\
\left(10^{-6} /{ }^{\circ} \mathrm{C}\right)\end{array}$ & $\begin{array}{l}\alpha_{2} \\
\left(10^{-6} /{ }^{\circ} \mathrm{C}\right)\end{array}$ \\
\hline | 34.8 & 9.6 & 5.3 & 0.32 & 0.487 & 0.1265 & 37.12 \\
\hline
\end{tabular}

Table 2. Strength properties of AS4/8552. ${ }^{29,30}$

\begin{tabular}{|c|c|c|c|c|c|}
\hline $\begin{array}{l}X_{t} \\
(\mathrm{MPa})\end{array}$ & $\begin{array}{l}X_{c} \\
(\mathrm{MPa})\end{array}$ & $\begin{array}{l}Y_{t} \\
(\mathrm{MPa})\end{array}$ & $\begin{array}{l}Y_{c} \\
(\mathrm{MPa})\end{array}$ & $\begin{array}{l}S_{12} \\
(\mathrm{MPa})\end{array}$ & $\begin{array}{l}S_{23} \\
(\mathrm{MPa})\end{array}$ \\
\hline 207 & $-|53|$ & 80.7 & -199.8 & $1 \mid 4.5$ & 102.7 \\
\hline
\end{tabular}

\section{Comparison between theoretical, FEM, and experi- mental results}

$\left[\theta_{12}\right]_{T}$ Off-axis laminates. In Figures 3-5, analytical and numerical predictions of $M_{\max }$ obtained as a function of the orientation angle, $\theta$, using the chosen failure criteria for unidirectional specimens, $\left[\theta_{12}\right]_{\mathrm{T}}$, are compared with the experimental results. Maximum allowable bending moment, $M_{\max }$, is shown in logarithmic scale of base 2 in order to better reveal how the predictions compare with the empirical results at quite different load levels. Table 3 presents the average values, $\mu$, and the coefficients of variation, $\mathrm{CoV}(\%)$, of experimentally determined maximum allowable moment resultants, $M_{\max }$. CoV is the ratio of standard deviation to average. The table also gives the percentage of error in the predictions of the criteria obtained based on FEA. Because quadric surfaces and modified quadric surfaces give similar predictions, the results of modified quadric surfaces are omitted in the table. Figure 3 and Table 3 show that FEM-based predictions of Tsai-Wu, Tsai-Hill, Hoffman, quadric surfaces, modified quadric surfaces, and Norris criteria are very close to the experimental results. The average error is about $11-12 \%$. Considering the experimental scatter (average $\mathrm{CoV}$ is $10 \%$ ), the differences in the predicted failure levels are not significant. In general, the predictions of quadric surfaces are more conservative. As it is shown in the figures, $75^{\circ}$-specimens have lower strength than $90^{\circ}$ specimens. All of these criteria predict the strength to be minimum for values of $\theta$ less than $90^{\circ}$, but only Tsai$\mathrm{Wu}$ and quadric surfaces predict lower strength for $75^{\circ}$; the trend predicted by quadric surfaces reveals this feature noticeably as opposed to Tsai-Wu. Analytical predictions of Tsai-Wu, Tsai-Hill, and Hoffman are close to FEM results, but slightly non-conservative. On the other hand, quadric surfaces, modified quadric surfaces, and Norris criteria overestimate the failure loads based on analytically found stress states. Norris 

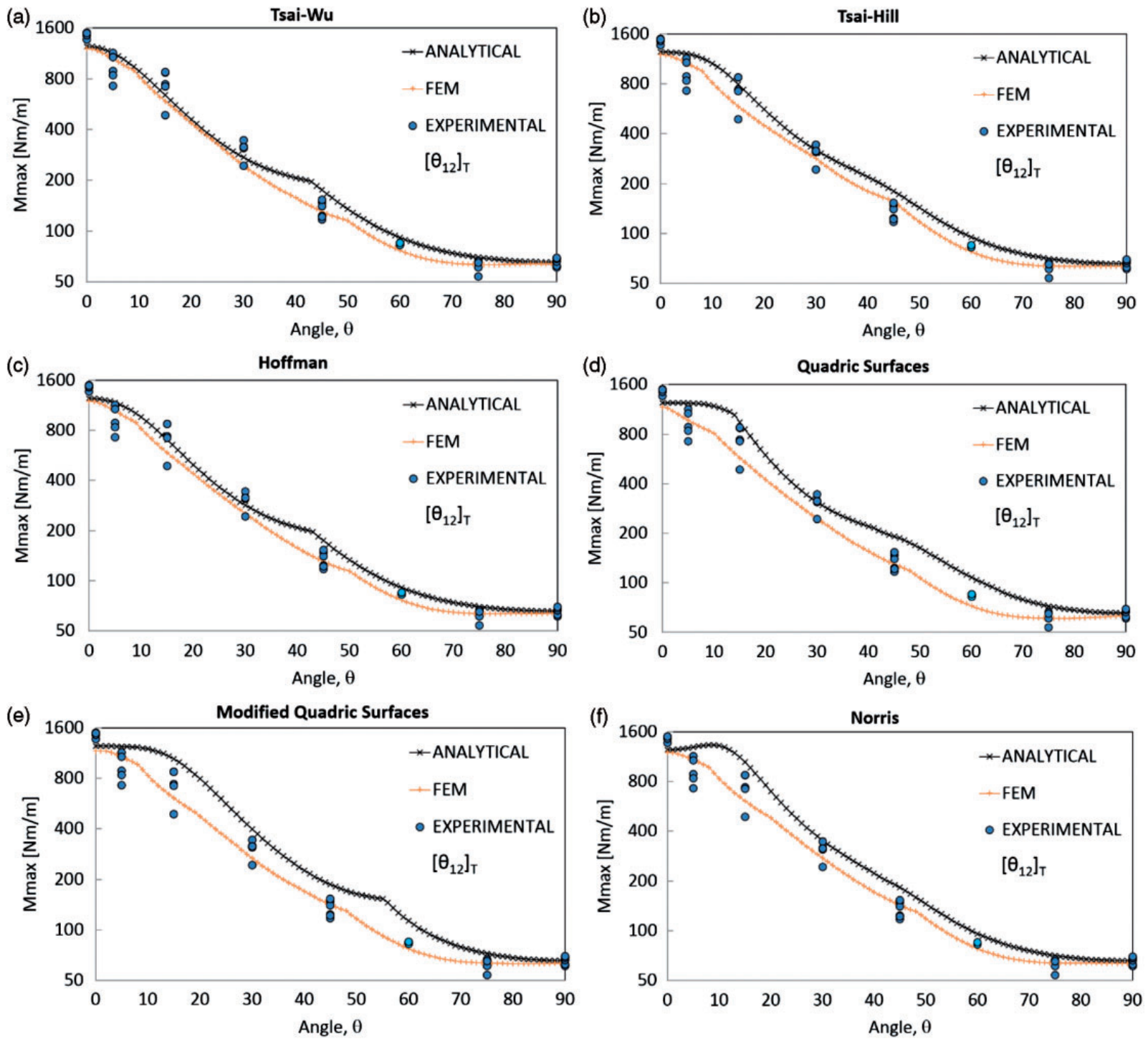

Figure 3. Comparison between the analytical and finite element $M_{\max }$ predictions obtained using (a) Tsai-Wu, (b) Tsai-Hill, (c) Hoffman, (d) the quadric surfaces (e) the modified quadric surfaces, and (f) Norris criteria for off-axis $\left[\theta_{12}\right]_{T}$ specimens with the experimental results.

criterion predicts increasing strength as $\theta$ is changed from $0^{\circ}$ to $9^{\circ}$, which contradicts the empirically determined trend.

Figure 4 shows the predictions of maximum stress, maximum strain, and Hashin criteria. All of these criteria are physically based, i.e. they can predict the failure mode of laminates. These criteria estimate a slight increase in strength in the first few degrees of the orientation angle, which is difficult to explain physically. Additionally, the failure trends of these criteria do not show a decrease in strength at $75^{\circ}$-orientation angle. As it is seen in the figures, these criteria overestimate the average strength of laminates with $5^{\circ}$ orientation. The FEM-based predictions of these criteria again correlate better with the experimental results as compared to the analytical ones. The reason for this may be attributed to the boundary conditions of the analytical model, which do not exactly reflect the experimental conditions and partially to the use of $2 \mathrm{D}$ stress state instead of 3D stress state. The predictions of the criteria based on FE results are not exactly the same for specimens having $0^{\circ}$ or $90^{\circ}$ orientation angle; since the FE model accounts for Poisson's effect, a multiaxial stress state is obtained even for $=0^{\circ}$ or $90^{\circ}$.

Figure 5 gives the experimental results together with the predictions of all the failure criteria for unidirectional laminates, $\left[\theta_{12}\right]_{\mathrm{T}}$, based on the $\mathrm{FE}$ model. Quadric surfaces is slightly better in that its predictions are either consistent with the experimental results (the average error is $10.9 \%$ ) or conservative. 

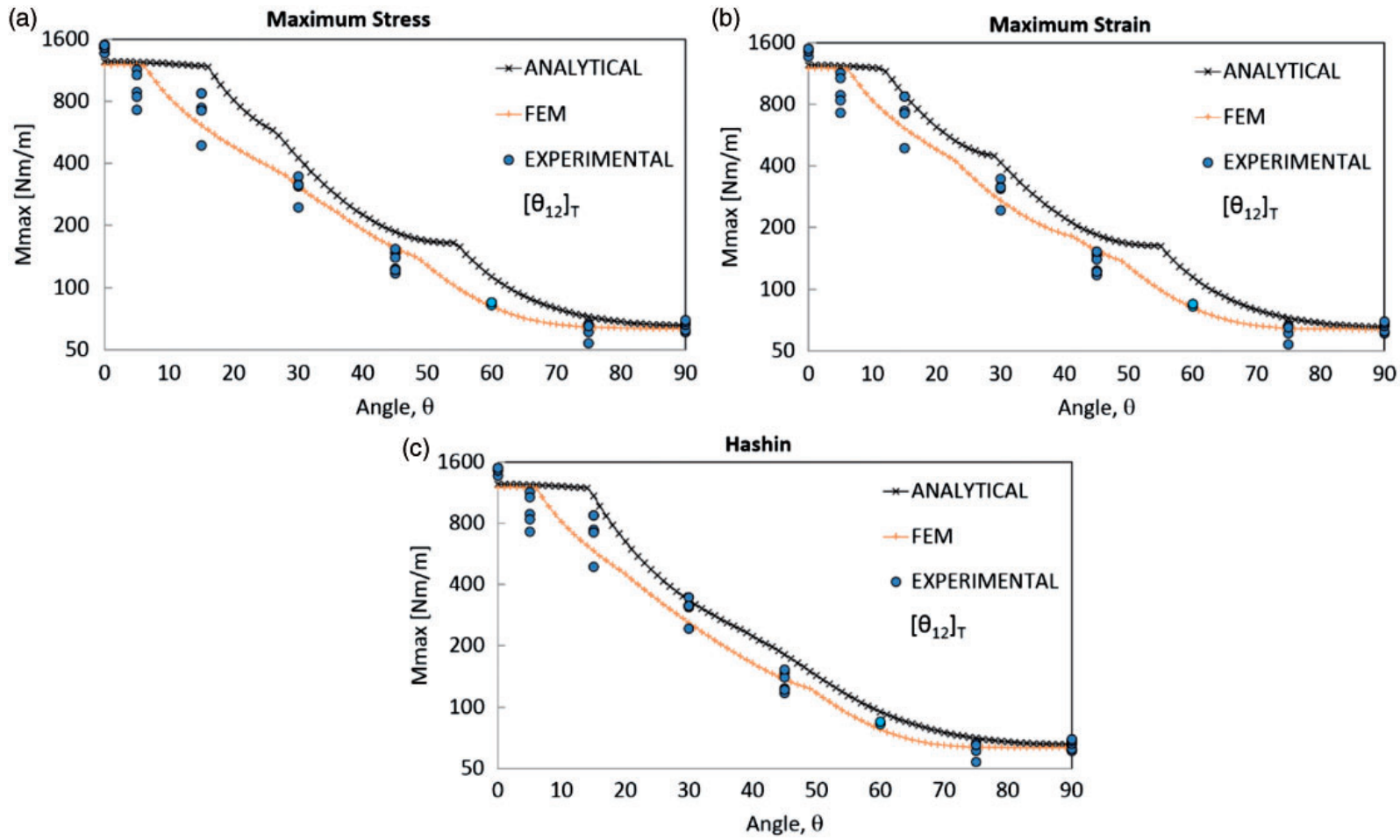

Figure 4. Comparison between the analytical and finite element $M_{\max }$ predictions obtained using (a) maximum stress, (b) maximum strain, and (c) Hashin criteria for off-axis $\left[\theta_{12}\right]_{T}$ specimens with the experimental results.

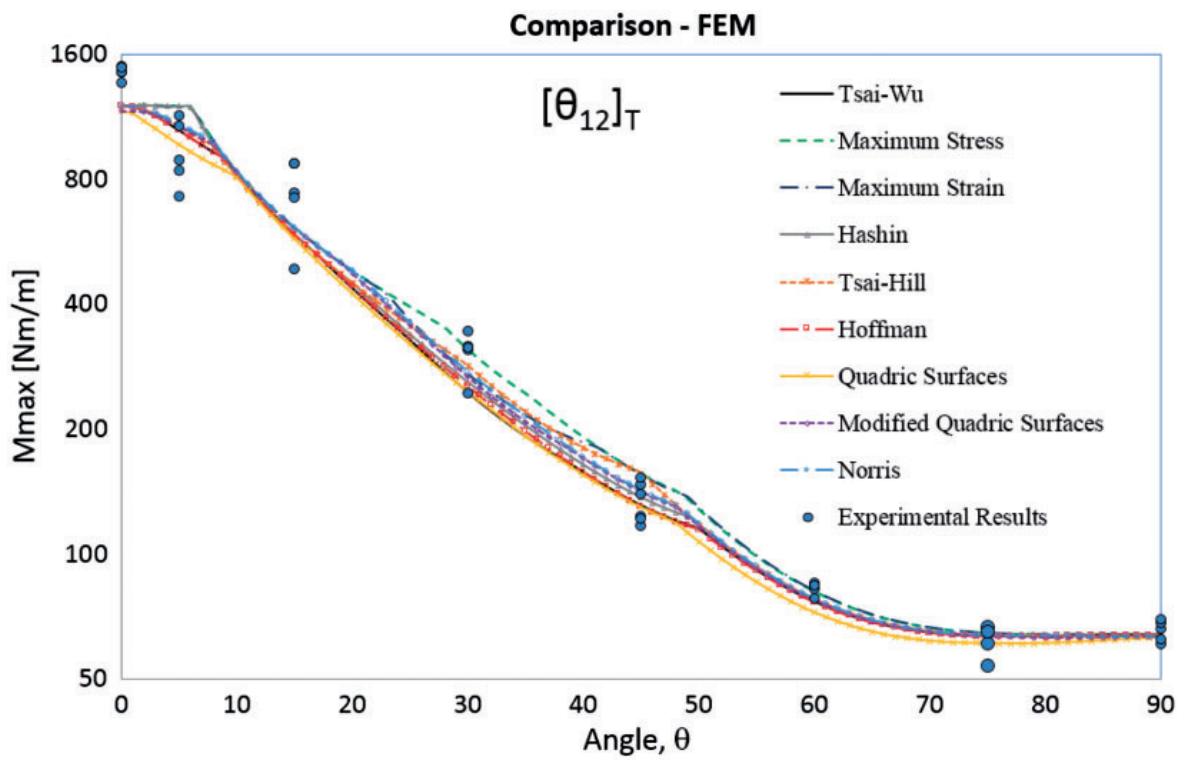

Figure 5. $M_{\max }$ predictions of the failure criteria for unidirectional laminates $\left[\theta_{12}\right]_{\mathrm{T}}$ based on the FE model.

In Figure 6, photographs of the bottom surfaces of the failed off-axis specimens, $\left[\theta_{12}\right]_{\mathrm{T}}$, can be seen. Fiber directions are shown by arrows. Schematics of various failure modes can be seen in Figure 7. The main failure mode is fiber breakage up to $15^{\circ}$. Delaminations are observed to occur, but after intralaminar failure. For specimens with an angle of $30^{\circ}$ and above, the main failure mode is matrix cracking; the final catastrophic failure occurs due to matrix cracking. The fracture surfaces in the $\left[45_{12}\right]_{\mathrm{T}}$, $\left[60_{12}\right]_{\mathrm{T}}$ and $\left[90_{12}\right]_{\mathrm{T}}$ specimens are parallel to the fiber direction. In some specimens, $\left[0_{12}\right]_{\mathrm{T}},\left[5_{12}\right]_{\mathrm{T}},\left[15_{12}\right]_{\mathrm{T}},\left[30_{12}\right]_{\mathrm{T}}$, damage starts close to the upper supports, which may be 
Table 3. For off-axis $\left[\theta_{12}\right]_{\mathrm{T}}$ laminates, the average value, $\mu$, and the coefficient of variation, CoV (\%), of experimentally determined maximum allowable moments resultants, $M_{\max }$, and the percentage error in the predictions of the criteria based on FEA.

\begin{tabular}{|c|c|c|c|c|c|c|c|c|c|c|}
\hline \multirow[b]{2}{*}{$\theta$} & \multicolumn{2}{|c|}{$M_{\max }(\mathrm{Nm} / \mathrm{m})$} & \multicolumn{8}{|c|}{ Error $(\%)\left(100 *\left(x_{\text {pred }}-x_{\exp }\right) / x_{\exp }\right)$} \\
\hline & $\mu$ & CoV (\%) & Tsai-Wu & Tsai Hill & Hoff-man & Norris & Quad Surf & Max stress & Max strain & Hashin \\
\hline $0^{\circ}$ & 1452 & 3.2 & -17.1 & -17.4 & -17.2 & -17.3 & -19.7 & -17.4 & -17.4 & -17.4 \\
\hline $5^{\circ}$ & 933 & 16.3 & 12.6 & 14.5 & 12.3 & 16.1 & 4.0 & 28.3 & 28.2 & 28.3 \\
\hline $15^{\circ}$ & 740 & 19.1 & -20.4 & -20.9 & -20.6 & -17.5 & -22.3 & -17.4 & -17.4 & -20.7 \\
\hline $30^{\circ}$ & 306 & 10.9 & -19.8 & -7.2 & -17.3 & -10.1 & -19.5 & 1.5 & -11.2 & -15.2 \\
\hline $45^{\circ}$ & 130 & 9.0 & 0.7 & 20.4 & 0.2 & 9.5 & -0.2 & 19.9 & 19.5 & 5.4 \\
\hline $60^{\circ}$ & 83 & 2.8 & -7.2 & -6.1 & -7.6 & -5.8 & -12.5 & -1.9 & -1.5 & -6.0 \\
\hline $75^{\circ}$ & 58 & 14.9 & 9.6 & 10.0 & 9.5 & 10.1 & 5.5 & 11.4 & 11.5 & 10.0 \\
\hline $90^{\circ}$ & 65 & 5.1 & -2.3 & -3.2 & -2.9 & -3.2 & -3.5 & -3.2 & -2.6 & -3.2 \\
\hline \multicolumn{3}{|c|}{ Average Error (\%) } & 11.2 & 12.5 & 10.9 & 11.2 & 10.9 & 12.6 & 13.7 & 13.3 \\
\hline
\end{tabular}

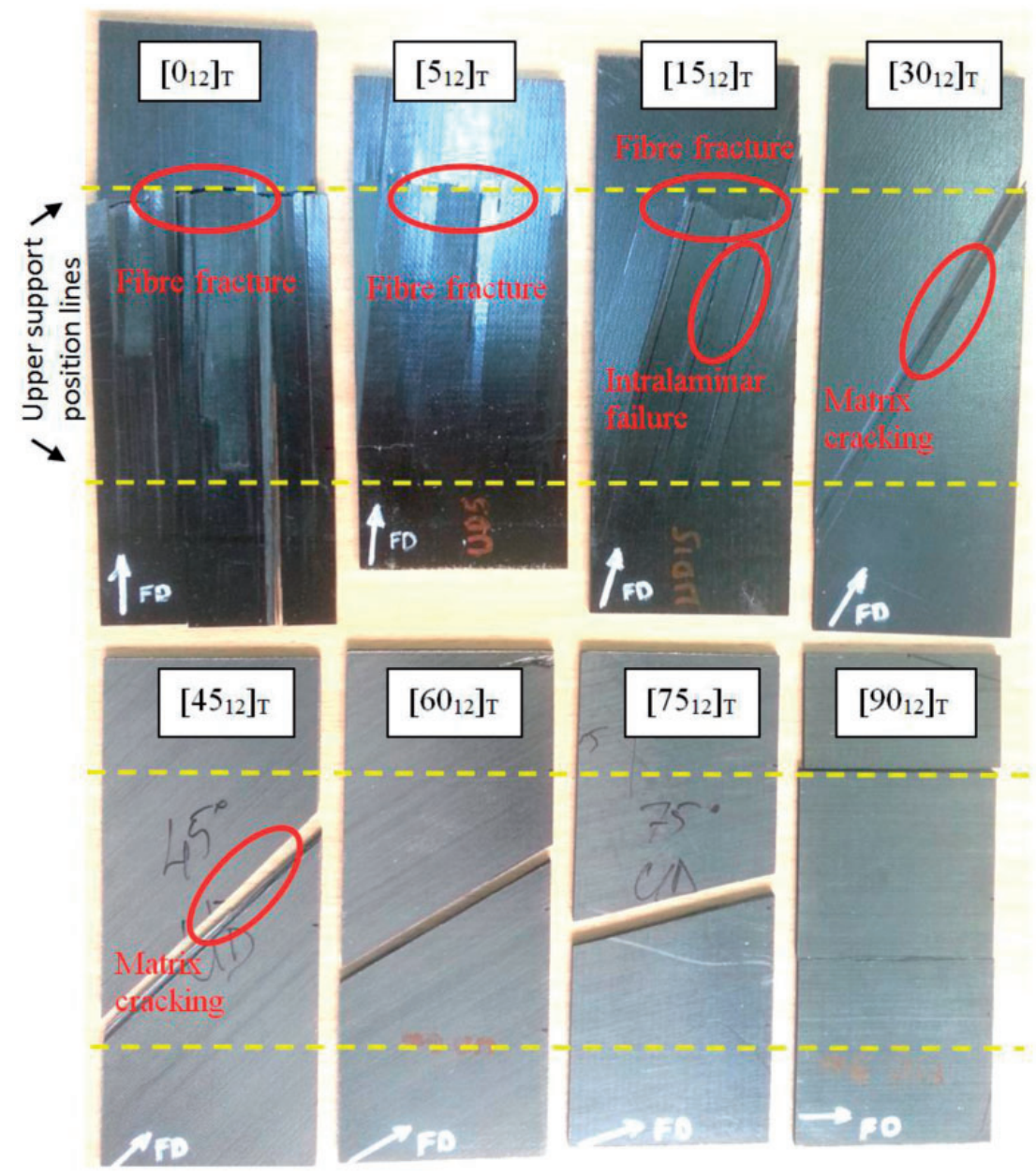

Figure 6. Photographs of the off-axis failed specimens, $\left[\theta_{12}\right]_{\mathrm{T}}$.

due to stress concentration created by the supports. However, considering that the analytical structural analysis does not take into account stress concentration and the predictions of the failure criteria based on the analytical solution are satisfactory, the effect of stress concentration can be assumed to be small. In some others, $\left[60_{12}\right]_{\mathrm{T}},\left[75_{12}\right]_{\mathrm{T}},\left[90_{12}\right]_{\mathrm{T}}$, on the other hand, fracture surfaces are away from the support locations. 

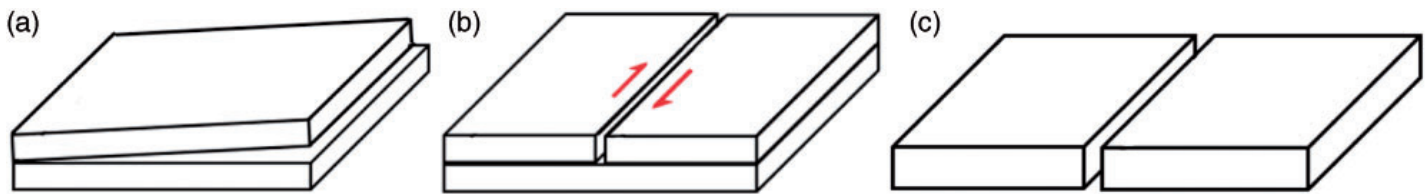

Figure 7. Schematics of the failure modes: (a) delamination, (b) intralaminar failure, and (c) catastrophic matrix cracking.
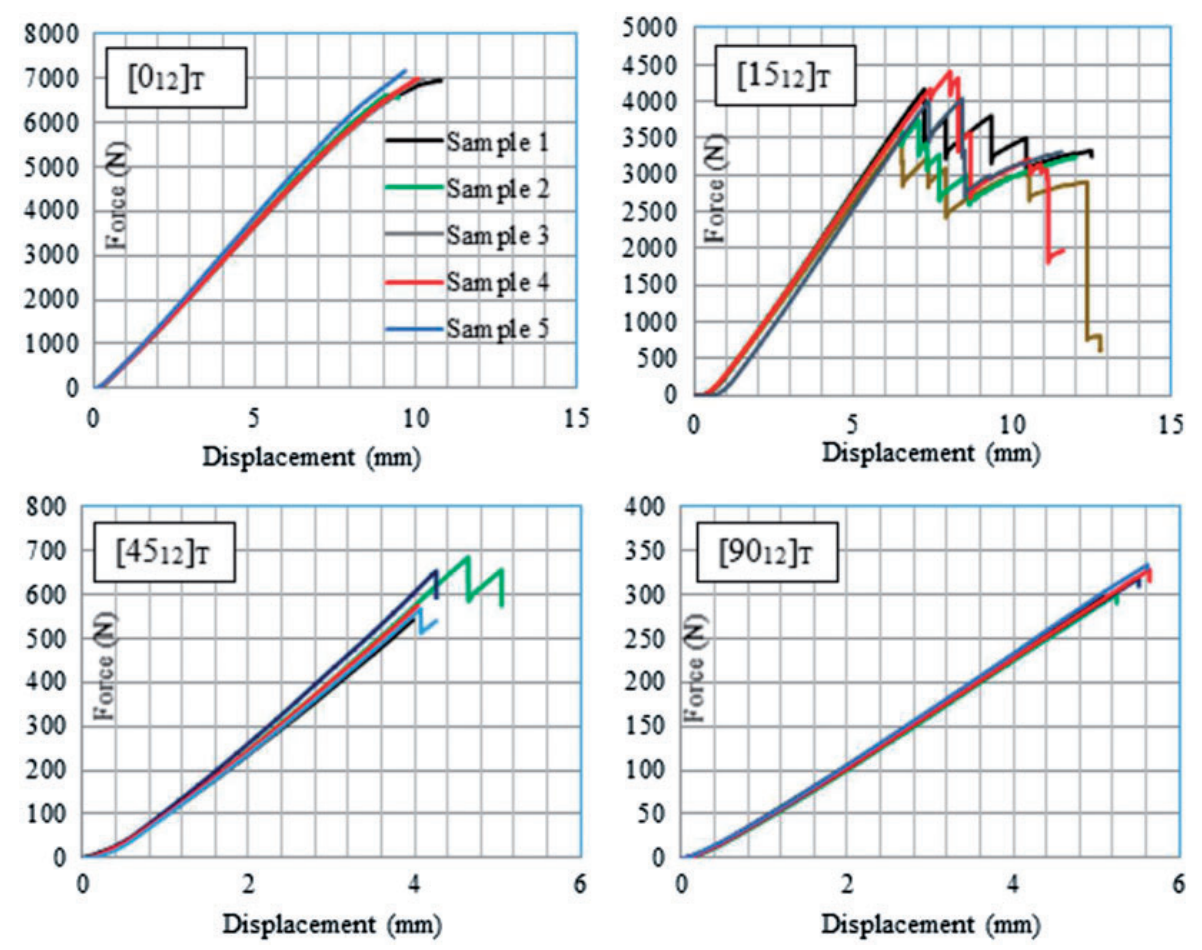

Figure 8. Force-displacement graphs of tested off-axis specimens, $\left[\theta_{12}\right]_{\mathrm{T}}$.

Plots of the applied force on the upper supports, $2 F$, versus their displacements, $\delta$, (see Figure 2 for $F$ and $\delta$ ) for off-axis specimens are given in Figure 8. These plots can be used to determine the first and final failure loads of the specimens. In the specimens with layup $\left[0_{12}\right]_{\mathrm{T}}$, $\left[30_{12}\right]_{\mathrm{T}},\left[60_{12}\right]_{\mathrm{T}},\left[75_{12}\right]_{\mathrm{T}}$, and $\left[90_{12}\right]_{\mathrm{T}}$, sudden failure is observed, while in the specimens with $\left[5_{12}\right]_{\mathrm{T}}$, and $\left[15_{12}\right]_{\mathrm{T}}$, zigzag deformation is seen. This zigzag deformation shows the interaction of different failure modes and progressive failure behavior.

The predictions of $M_{\max }$ based on analytical and FE models are about the same for $90^{\circ}$ laminates and consistent with the experimental result as expected. However, the estimated failure load for $\theta=0^{\circ}$ is about $17 \%$ lower than the empirically determined level, which is $1452 \mathrm{Nm} / \mathrm{m}$ on average. This may be the result of the peculiar failure behavior of $0^{\circ}$ laminates under bending. The maximum normal stress criterion predicts fiber breakage at the bottom of the plate, which is under tension, when $\sigma_{x x}=X_{t}=2207 \mathrm{MPa}$ at $M_{x x}=1793 \mathrm{Nm} / \mathrm{m}$, but before that level is reached, it predicts fiber buckling at the top of the plate, which is under compression, when $\sigma_{x x}=X_{c}=-1531 \quad \mathrm{MPa} \quad$ at $M_{x x}=1244 \quad \mathrm{Nm} / \mathrm{m}$. Therefore, the model estimates the first-ply-failure load as $1244 \mathrm{Nm} / \mathrm{m}$. However, even if the top-most fibers would buckle in the tests and the stiffness of the plate would slightly decrease, this is barely noticeable from the macro-behavior of the laminate. Further increase in the load leads to further decrease in the stiffness due to more extensive micro-buckling. Only at higher load levels, this trend becomes noticeable. In most of the specimens, fracture occurs due to breaking of fibers at the bottom before significant loss occurs in stiffness as seen in the force - displacement curves for $\left[0_{12}\right]_{\mathrm{T}}$ specimens shown in Figure 8.

Figure 9 shows the distribution of $\sigma_{x x}$ component of stress at the bottom of the specimen with layup configuration $\left[0_{12}\right]_{\mathrm{T}}$. The load is just sufficient to cause firstply failure according to the maximum stress theory; the mode of failure is due to fiber buckling, which occurs at the top of the laminate, where $\sigma_{x x}=X_{c}=-1531 \mathrm{MPa}$. Although at the bottom, the maximum value of $\sigma_{x x}$ is 


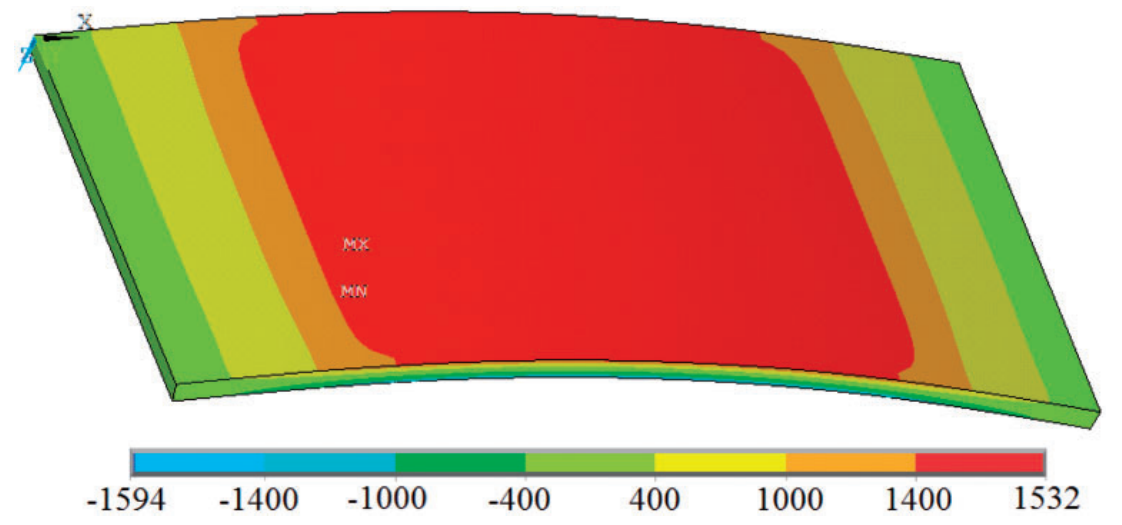

Figure 9. The distribution of $\sigma_{x x}$ component of stress in the specimen having fiber orientation $\theta=0^{\circ}$.
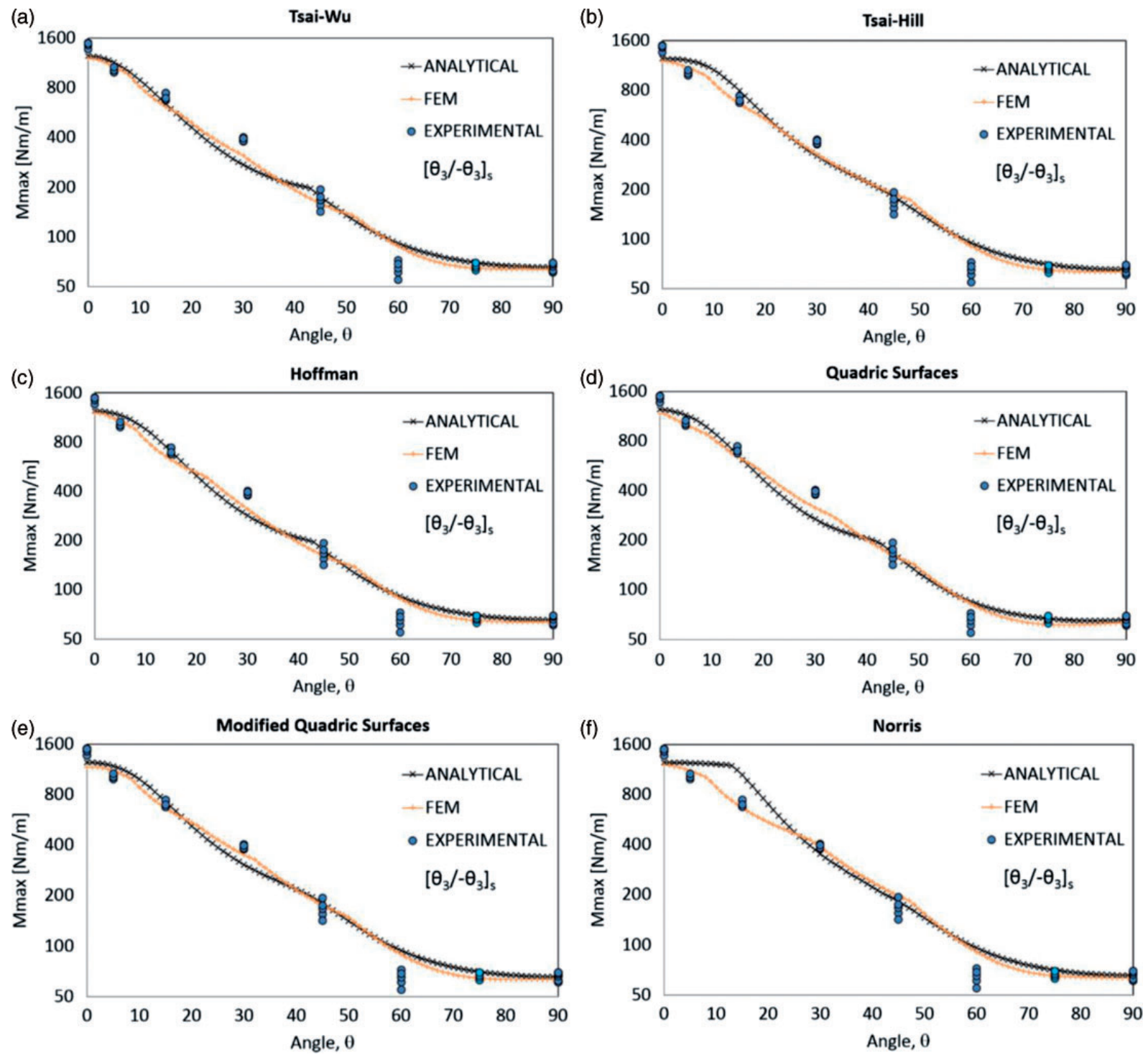

Figure 10. Comparison between the analytical and finite element $M_{\max }$ predictions obtained using (a) Tsai-Wu, (b) Tsai-Hill, (c) Hoffman, (d) quadric surfaces (e) modified quadric surfaces and (f) Norris criteria for balanced and symmetric angle-ply $\left[\theta_{3} /-\theta_{3}\right]_{\mathrm{s}}$ specimens with the experimental results (excluding the effects of residual stresses). 
equal to $1532 \mathrm{MPa}$ in tension, at the top surface, the maximum compressive stress is $-1594 \mathrm{MPa}$ because of stress concentration due to concentrated displacement boundary conditions at the region in contact with the upper support; for this reason, this region is not included in failure assessment.

Balanced and symmetric angle-ply laminates, $\left[\theta_{3} /-\theta_{3}\right]_{s}$. In Figures 10-13, analytical and finite element $M_{\max }$ predictions obtained using the chosen failure criteria for balanced and symmetric angle-ply $\left[\theta_{3} /-\theta_{3}\right]_{\mathrm{s}}$ specimens are compared with the experimental results. Table 4 presents the average values, $\mu$, and the coefficients of variation, $\mathrm{CoV}(\%)$, of experimentally determined maximum allowable moment resultants, $M_{\max }$, for angleply laminates. The table also gives the percentage of error in the predictions of the criteria based on FEA results excluding the effects of residual stresses.

In four-point bending of balanced angle-ply specimens, the loading is not pure bending. When the plate is bent, twisting curvature tends to develop due to bending-twisting coupling, but straight and rigid supports prevent development of twisting curvature in the contact region, and therefore the supports also cause twisting moment, $M_{x y}$. In a smaller extent, $M_{y y}$ may also develop due to Poisson's effect. Nevertheless, predominant loading is $M_{x x}$. For this reason, the level of $M_{x x}$ at the onset of damage is shown in the graphs as the failure load.

Figures 10 and 11 present the predictions of the criteria excluding residual stresses. Predictions of Tsai-Wu, Tsai-Hill, Hoffman, quadric surfaces, modified quadric surfaces, and Norris criteria are very close to each other as shown in Figure 10. Norris is more on the non-conservative side, while quadric surfaces are on the conservative side. The predictions correlate well with the experimental results except for $\theta=60^{\circ}$. They all overestimate the strength of $\left[60_{3} /-60_{3}\right]_{\mathrm{s}}$ laminate. The average error is in the range of $11-13 \%$; quadratic surfaces have the lowest error with $11.3 \%$. Besides, they all fail to estimate the failure trend that the minimum strength occurs at about $60^{\circ}$. The predicted failure trend is a continuously decreasing strength from $0^{\circ}$ to $90^{\circ}$. As in the unidirectional laminates, maximum stress, maximum strain, and Hashin criteria predict increasing strength up to $3^{\circ}$ as shown in Figure 11; otherwise, the predicted trend is similar to the others; the average error is about $13-16 \%$, which is slightly worse than the others. Finite element and analytical model-based predictions of Tsai$\mathrm{Wu}$, Tsai-Hill, Hoffman, quadric surfaces, and modified quadric surfaces are close to each other; the others show some discrepancies.
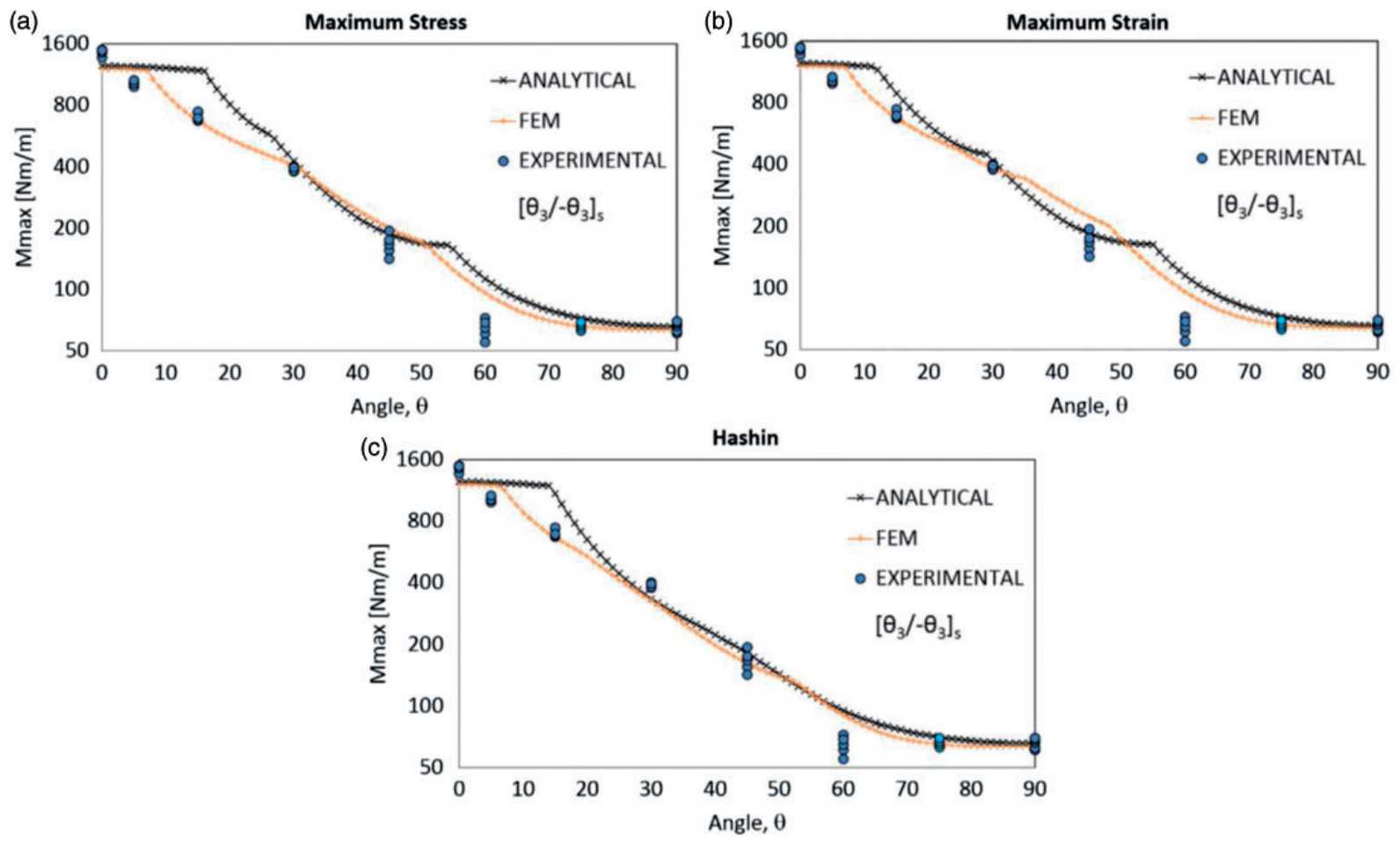

Figure II. Comparison between the analytical and finite element $M_{\max }$ predictions obtained using (a) Maximum stress, (b) Maximum strain, (c) Hashin criteria for balanced and symmetric angle-ply $\left[\theta_{3} /-\theta_{3}\right]_{s}$ specimens with the experimental results (excluding the effect of residual stresses). 

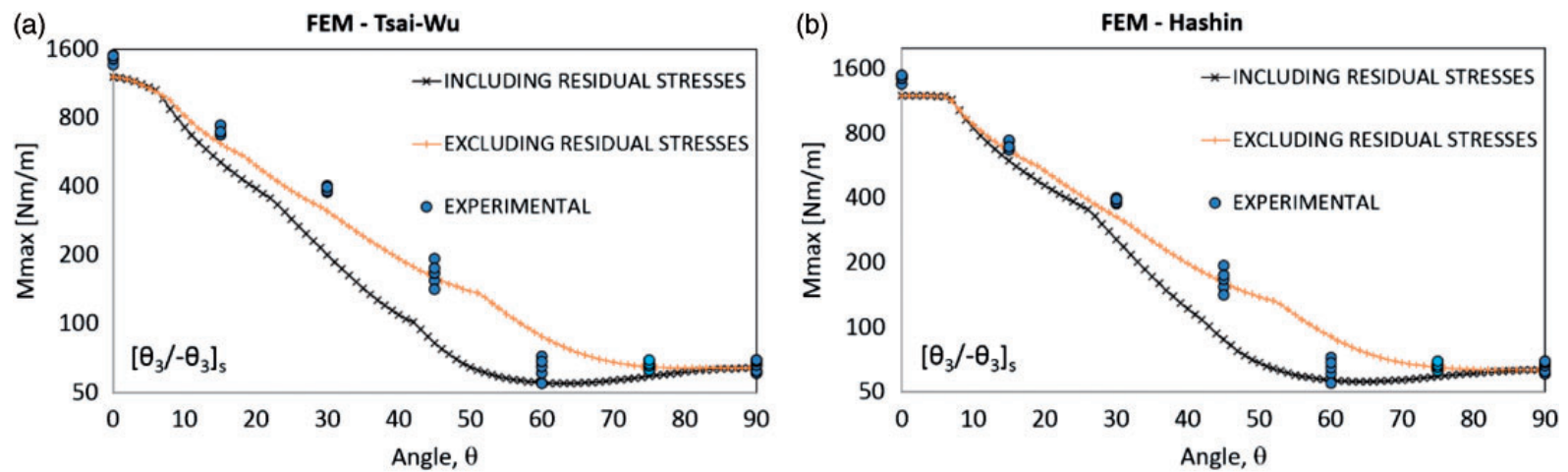

Figure 12. Comparison between the effect of residual stresses on the finite element model based $M_{\text {max }}$ predictions obtained using (a) Tsai-Wu and (b) Hashin for balanced and symmetric angle-ply $\left[\theta_{3} /-\theta_{3}\right]_{\mathrm{s}}$ specimens with the experimental results.

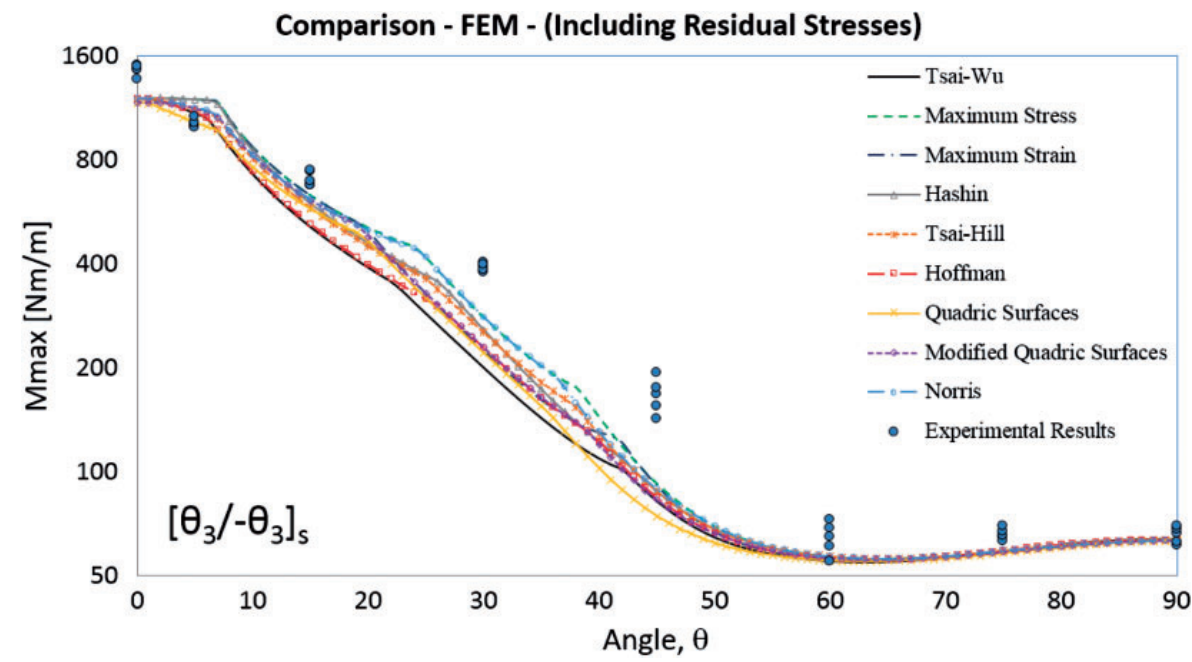

Figure 13. $M_{\max }$ predictions for $\left[\theta_{3} /-\theta_{3}\right]_{s}$ configuration based on the finite element model including residual stresses.

Table 4. For symmetric angle-ply $\left[+\theta_{3} /-\theta_{3}\right]_{s}$ laminates, the average value, $\mu$, and the coefficient of variation, CoV (\%), of experimentally determined maximum allowable moment resultants, $M_{\max }$, and the percentage error in the predictions of the criteria based on FEA excluding the effects of residual stresses.

\begin{tabular}{|c|c|c|c|c|c|c|c|c|c|c|}
\hline \multirow[b]{2}{*}{$\theta$} & \multicolumn{2}{|c|}{$M_{\max }(\mathrm{Nm} / \mathrm{m})$} & \multicolumn{8}{|c|}{ Error $(\%)\left(100 *\left(x_{\text {pred }}-x_{\exp }\right) / x_{\exp }\right)$} \\
\hline & $\mu$ & CoV (\%) & Tsai-Wu & Tsai Hill & Hoff-man & Norris & Quad Surf & Max Stress & Max Strain & Hashin \\
\hline $0^{\circ}$ & 1452 & 3.2 & -17.1 & -17.4 & -17.2 & -17.4 & -19.7 & -17.4 & -17.4 & -17.4 \\
\hline $5^{\circ}$ & 1018 & 2.5 & 5.7 & 7.9 & 5.8 & 8.9 & -1.5 & 17.4 & 17.3 & 17.4 \\
\hline $15^{\circ}$ & 704 & 4.3 & -12.6 & -5.9 & -11.5 & -5.4 & -9.0 & -4.5 & -4.5 & -5.5 \\
\hline $30^{\circ}$ & 390 & 2.4 & -20.2 & -15.9 & -20.2 & -1.0 & -19.3 & 3.2 & -1.4 & -16.1 \\
\hline $45^{\circ}$ & 166 & 10.5 & -4.2 & 13.3 & -2.8 & 18.5 & -2.3 & 20.4 & 34.2 & -2.7 \\
\hline $60^{\circ}$ & 64 & 9.4 & 37.0 & 40.7 & 37.2 & $4 I .1$ & 28.2 & 49.4 & 48.8 & 40.7 \\
\hline $75^{\circ}$ & 66 & 3.5 & -1.6 & -1.2 & -1.6 & -1.0 & -6.6 & 0.4 & 0.4 & $-I .1$ \\
\hline $90^{\circ}$ & 65 & 5.1 & -2.3 & -3.3 & -2.9 & -3.2 & -3.6 & -3.3 & -2.6 & -3.2 \\
\hline \multicolumn{3}{|c|}{ Average error (\%) } & 12.6 & 13.2 & 12.4 & 12.1 & 11.3 & 14.5 & 15.8 & 13.0 \\
\hline
\end{tabular}


A comparison of FEM-based predictions of $M_{\max }$ obtained using Tsai-Wu and Hashin criteria including and excluding the residual stresses can be seen in Figure 12. Residual stresses do not develop in unidirectional laminates with $\theta=0^{\circ}$ and $\theta=90^{\circ}$. Accordingly, no difference exists in the predicted failure loads for these laminates. The largest residual stress in the transverse direction is predicted to occur at $\theta=45^{\circ}$ with a magnitude of about $50 \mathrm{MPa}$. Considering that the transverse strength of the material is $81 \mathrm{MPa}$, significant portion of the strength is degraded due to the residual stresses. If the structural analysis is carried out accounting for the residual stresses, the failure criteria significantly underestimate the failure loads for $\theta=30^{\circ}$ and $\theta=45^{\circ}$; they slightly underestimate for $\theta=15^{\circ}, \theta=60^{\circ}$, and $\theta=75^{\circ}$. Underestimation may be attributed to the viscoelastic properties of polymerbased composites. Residual stresses developed during curing partially relax in time. Mite and $\mathrm{Kim}^{31}$ indicated $20 \%$ stress relaxation for AS4/3501-6. Because the

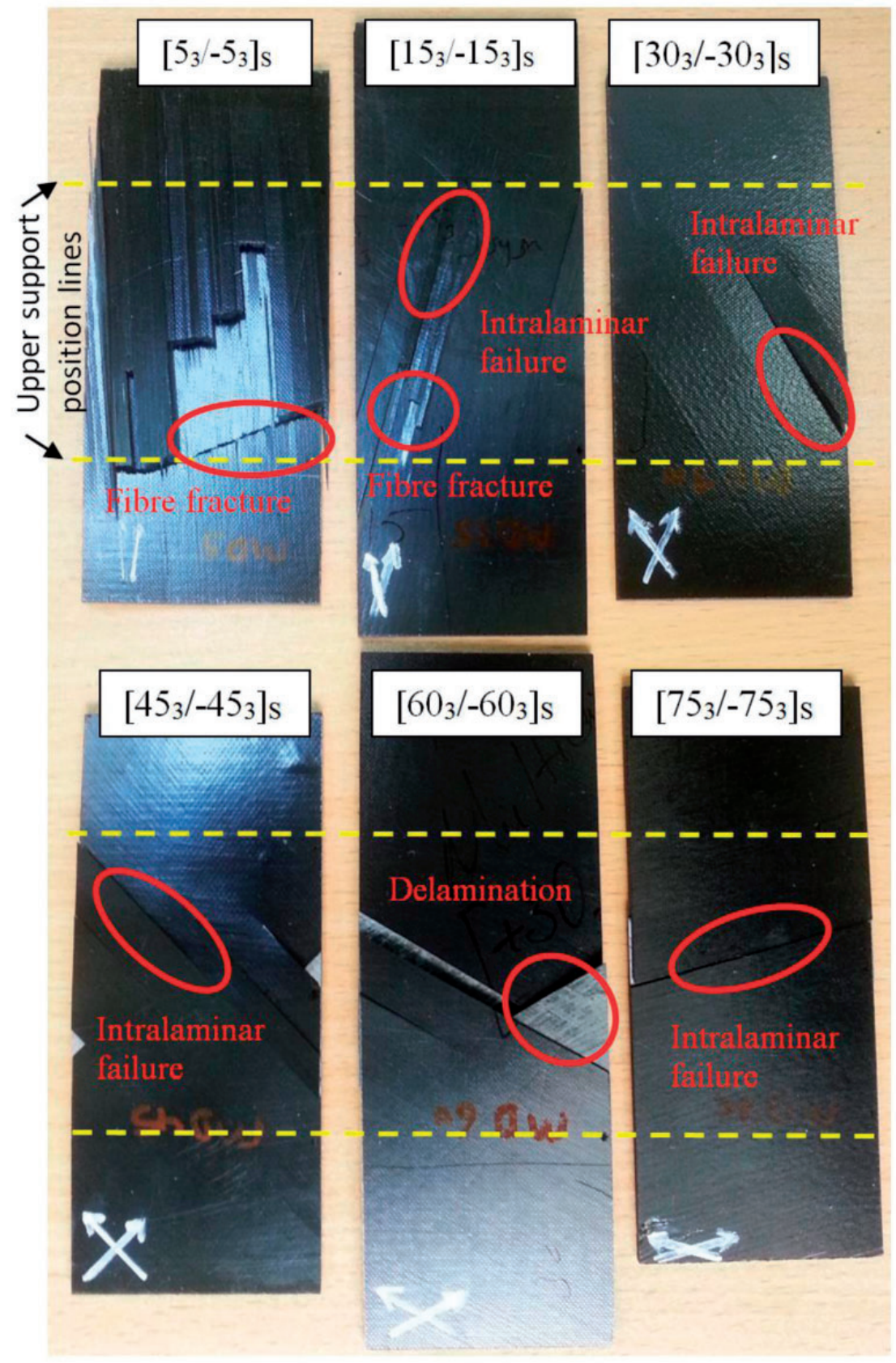

Figure 14. Photographs of the failed symmetric $\left[\theta_{3} /-\theta_{3}\right]_{\mathrm{s}}$ angle ply specimens. 
structural model does not account for viscoelastic effects, it is not surprising that the criteria overestimate the effect of residual stresses and underestimate the strength. Because of underestimation, accuracy of the predictions becomes worse; average errors in the predictions rise to levels of $18-22 \%$. On the other hand, it is noteworthy that if the residual stresses are included in the structural model, the predicted failure trends better correlate with the experimental results, i.e. tendencies of change in strength with the change in $\theta$ are similar. For example, the laminate strength is predicted to take its minimum value for angles about $60^{\circ}$ as revealed by the experiments; after that, the strength increases up to $\theta=90^{\circ}$. On the other hand, if the residual stresses are not taken into account, continuous decrease in strength is predicted with increasing $\theta$.

The predictions obtained by all the selected criteria considering the residual stress are given in Figure 13. For values of $\theta$ larger than $50^{\circ}$, the differences between the predictions are insignificant (less than 3\%). Below $50^{\circ}$, the differences are small considering the experimental scatter. Maximum stress, maximum strain, and Hashin again predict higher strength for the first few degrees of $\theta$ compared to $0^{\circ}$.

Photographs of the bottom surfaces of failed symmetric angle-ply specimens, $\left[\theta_{3} /-\theta_{3}\right]_{\mathrm{s}}$, can be seen in Figure 14. Delamination and matrix cracking take place in all specimens. Fiber breakage occurs only in the specimens with layup configurations $\left[5_{3} /-5_{3}\right]_{\mathrm{s}}$ and $\left[15_{3} /-15_{3}\right]_{\mathrm{s}}$ and damage starts close to the upper supports, because these create stress concentration. For fiber angles larger than $15^{\circ}$, the main failure mode changes to intralaminar failure. Delaminations are observed to occur at a stage later than intralaminar failure. For larger angles, damage initiates away from the support locations.

Force-displacement plots of $\left[\theta_{3} /-\theta_{3}\right]_{\mathrm{s}}$ angle-ply specimens are given in Figure 15. Zigzag deformation behavior is observed as in the off-axis specimens of $\left[15_{12}\right]_{\mathrm{T}}$ (Figure 8 ). The main source of scatter observed in the experiments can be presumed to be manufacturing defects. The average of $\mathrm{CoV}$ (coefficient of variation) values given in Tables 3 and 4 is $10.2 \%$ for off-axis specimens and $5.1 \%$ for angle-ply specimens. Another source of scatter might be hand lay-up method. It can be seen in Figures 5 and 13 that there are less scatter in the samples of $\left[0_{12}\right]_{\mathrm{T}}$ and $\left[90_{12}\right]_{\mathrm{T}}$. This may partially be due to smaller error in the placement of the plies along the chosen orientation, considering that it is much easier to achieve the chosen stacking directions for these layups. Another source of scatter in strength is the differences in specimen thickness. The thickness varies from $2.17 \mathrm{~mm}$ to $2.24 \mathrm{~mm}$ with an average of $2.204 \mathrm{~mm}$.
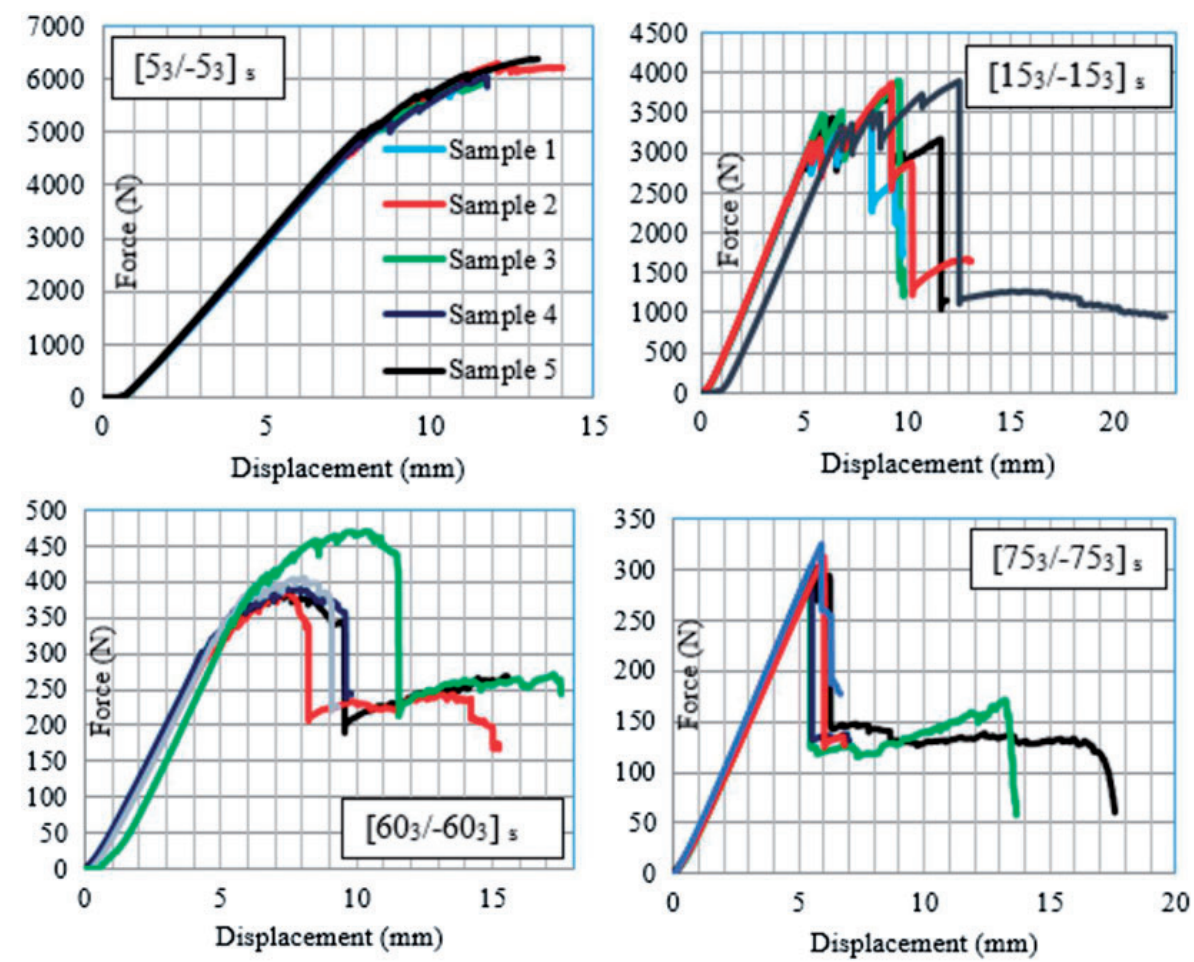

Figure 15. Force-displacement graphs of tested symmetric angle-ply specimens, $\left[\theta_{3} /-\theta_{3}\right]_{s}$. 


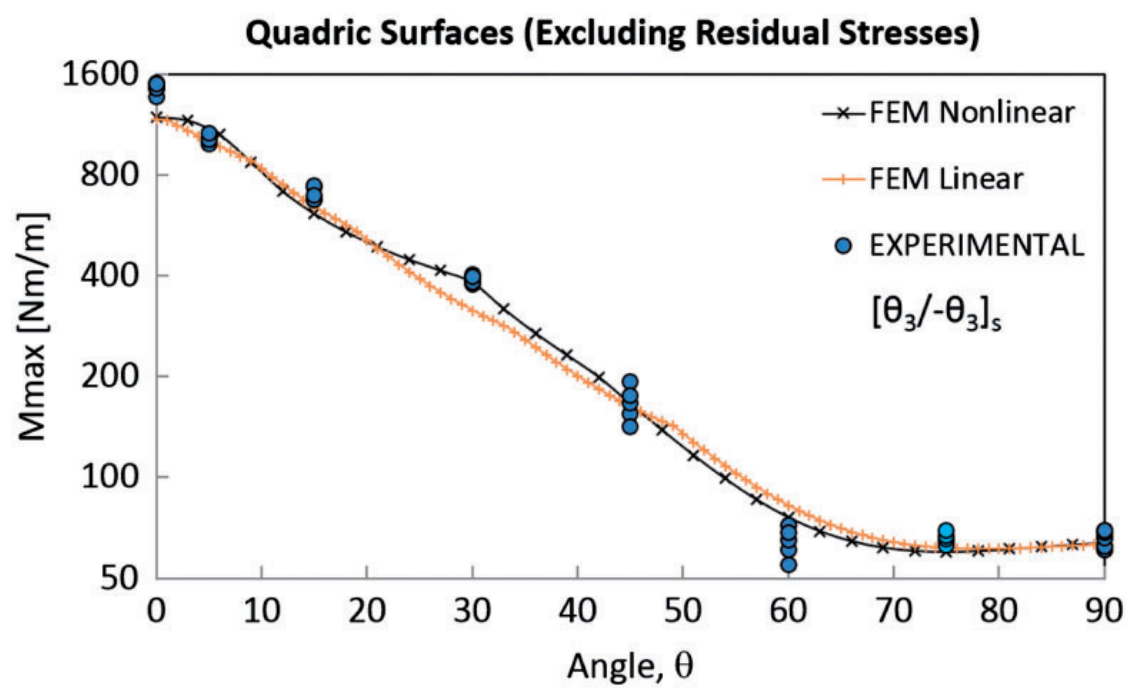

Figure 16. Comparison of the results of linear and nonlinear finite element model for angle-ply specimens.

\section{Comparison of predictions based on linear and nonlinear finite element models}

Although the material response can be considered to be linear as the force-displacement graphs show, assumption of geometric linearity is questionable considering that deflections are observed to be much larger than the thickness of the specimens $(2.21 \mathrm{~mm})$ during the fourpoint bending tests as Figure 15 indicates. The above presented predictions are obtained based on the linear finite element model, which determines the response of the specimens by taking the fibers at their initial positions. In order to estimate the effects of geometric nonlinearity, a nonlinear finite element model is developed that accounts for large rotations and deflections. As shown in Figure 16, the predicted failure loads based on the quadric surfaces are similar except for $\theta=30^{\circ}$. For this configuration, the nonlinear model estimates the failure load to be $20 \%$ higher than the linear model and much closer to the experimental result. The average error also reduces from $11.3 \%$ to $8.7 \%$.

\section{Predicted failure trends for in-plane loads}

The success of a failure criterion in predicting the failure behavior of a composite laminate for just one type of loading does not justify its use in design for an arbitrary loading. In the present study, analytical solutions are obtained for off-axis $\left(\left[\theta_{12}\right]_{\mathrm{T}}\right)$ and angleply $\left(\left[\theta_{3} /-\theta_{3}\right]_{\mathrm{s}}\right)$ laminates under in-plane uniaxial loading and the predicted failure trends are compared with the experimental results reported in the literature. For off-axis $\left(\left[\theta_{12}\right]_{\mathrm{T}}\right)$ laminates subjected to a uniaxial inplane load (only $N_{x x} \neq 0$ ), all of these failure criteria predict the maximum strength for $\theta=0^{\circ}$, except maximum stress and maximum strain criteria, which predict first an increase in strength with increasing $\theta$, then a decrease; this does not agree with the empirical data reported in the literature. ${ }^{24}$ If an angle-ply laminate $\left(\left[\theta_{3} /-\theta_{3}\right]_{\mathrm{s}}\right)$ is subjected to a uniaxial in-plane load, all the criteria except Hoffman predict decreasing strength with increasing $\theta$. Hoffman, on the other hand, predicts increasing strength until $\theta=6^{\circ}$. For materials having tensile strength in the fiber direction lower than the compressive strength like T300/5308, ${ }^{7}$ Tsai-Wu predicts the maximum strength for $\theta=10^{\circ}$, which is about $8 \%$ higher than the strength of $\left[0_{12}\right]_{\mathrm{T}}$. This does not comply with the experimental results. ${ }^{32}$ Hoffman gives even worse predictions; it estimates the strength of $\left[12_{3} /-12_{3}\right]_{\mathrm{S}}$ laminate $25 \%$ higher than $\left[0_{12}\right]_{\mathrm{T}}$ laminate. Among the criteria considered in this study, quadric surfaces criterion is better in correctly predicting the failure trends for the chosen configurations $\left[\theta_{12}\right]_{\mathrm{T}}$ and $\left[+\theta_{3} / \theta_{3}\right]_{\mathrm{s}}$ and loading conditions.

\section{Conclusions}

In this study, the failure behavior of $\left[\theta_{12}\right]_{\mathrm{T}}$ off-axis laminate and symmetric angle-ply $\left[\theta_{3} /-\theta_{3}\right]_{\mathrm{s}}$ laminates under four-point bending is investigated. A four-point bending test setup is designed and constructed such that intralaminar failure modes are more critical than delamination. Experiments are conducted for $\left[\theta_{12}\right]_{\mathrm{T}}$ and $\left[\theta_{3} /-\theta_{3}\right]_{\mathrm{s}}$ layup sequences for fiber angles of $0^{\circ}$, $5^{\circ}, 15^{\circ}, 30^{\circ}, 45^{\circ}, 60^{\circ}, 75^{\circ}$, and $90^{\circ}$. Both CLT and FEM are utilized to simulate the four-point bending tests. Maximum allowable moment resultant, $M_{\max }$, predictions of nine different failure criteria are compared with the experimental results. 
For unidirectional laminates, $\left[\theta_{12}\right]_{\mathrm{T}}$, finite element model based predictions of Tsai-Wu, Tsai-Hill, Hoffman, quadric surfaces, modified quadric surfaces, and Norris criteria are very close to the experimental results with an average error of $11-12 \%$. Maximum stress, maximum strain, and Hashin criteria predict a slight increase in strength in the first few degrees of the orientation angle, which is in conflict with the experimental findings. The strength of $\left[75_{12}\right]_{\mathrm{T}}$ laminates is found to be lower than that of $\left[90_{12}\right]_{\mathrm{T}}$ laminates. Only Tsai-Wu and quadric surfaces succeed in correctly predicting this failure trend.

As for angle-ply $\left[\theta_{3} /-\theta_{3}\right]_{\mathrm{s}}$ laminates, if the residual stresses are not included in the structural analysis, predictions of Tsai-Wu, Tsai-Hill, Hoffman, quadric surfaces, modified quadric surfaces, and Norris criteria correlate well with the experimental results except that they overestimate the strength of $\left[60_{3} /-60_{3}\right]_{\mathrm{s}}$ laminate. Besides, they all fail to predict the failure trend that the minimum strength occurs at about $60^{\circ}$. If the residual stresses are included, the criteria underestimate the failure loads.

The FEM-based predictions of the chosen failure criteria correlate better with the experimental results as compared to the analytical ones. The reason for this may be the better representation of the boundary conditions in the FE model and partially the use of 3D solid elements.

Correlation of the predicted failure trends with the experimental results is also examined for plates having the same configurations, $\left[\theta_{12}\right]_{\mathrm{T}}$ and $\left[\theta_{3} /-\theta_{3}\right]_{\mathrm{s}}$, subjected to uniaxial in-plane loads by comparing the predictions with previously reported experimental results. If the tensile strength of the material in the fiber direction is lower than its compressive strength, Tsai-Wu and Hoffman criteria predict an increase in strength under uniaxial in-plane loads as the fiber angle is varied from 0 to $10-12^{\circ}$, which is in conflict with the empirical results. Overall, quadric surfaces is better in predicting the failure trends for the chosen configurations $\left[\theta_{12}\right]_{\mathrm{T}}$ and $\left[+\theta_{3} /-\theta_{3}\right]_{\mathrm{s}}$ under uniaxial in-plane and out-of plane loading conditions.

\section{Declaration of Conflicting Interests}

The author(s) declared no potential conflicts of interest with respect to the research, authorship, and/or publication of this article.

\section{Funding}

The author(s) disclosed receipt of the following financial support for the research, authorship, and/or publication of this article: This paper is based on the work supported by the Scientific Research Projects of Bogazici University with the code number 7960-13A06P5.

\section{References}

1. Tsai SW and Wu EM. A general theory of strength for anisotropic materials. J Compos Mater 1971; 5: 58-80.

2. Hoffman O. The brittle strength of orthotropic materials. J Compos Mater 1967; 1: 200-206.

3. Yeh H-L. Quadric surfaces criterion for composite materials. J Reinf Plast Compos 2003; 22: 517-532.

4. Yeh H-L and Yeh H-Y. The modified quadric surfaces criterion for composite materials. $J$ Reinf Plast Compos 2002; 21: 277-289.

5. Norris CB. Strength of orthotropic materials subjected to combined stress. Forest Products Laboratory, Report no 1816, 1962.

6. Hashin Z. Failure criteria for unidirectional fiber composites. J Appl Mech 1980; 47: 329-334.

7. Akbulut $M$ and Sonmez FO. Design optimization of laminated composites using a new variant of simulated annealing. Comput Struct 2011; 89: 1712-1724.

8. Sandhu RS. A survey of failure theories of isotropic and anisotropic materials. Technical Report, OH: Air Force Flight Dynamics Laboratory Wright-Patterson AFB, 1972.

9. Paris F. A study of failure criteria of fibrous composite materials. Report NASA, CR-2001-210661, 2001.

10. Davila CG, Camanho PP and Rose CA. Failure criteria for FRP laminates. J Compos Mater 2005; 39: 323-345.

11. Soni SR. A Comparative study of failure envelopes in composite laminates. J Reinf Plast Compos 1983; 2: 34-42.

12. Hinton MJ, Kaddour AS and Soden PD. Failure criteria in fibre reinforced polymer composites: The World-wide failure exercise. Oxford: Elsevier, 2004.

13. Kaddour AS, Hinton MJ, Smith PA, et al. A comparison between the predictive capability of matrix cracking, damage and failure criteria for fibre reinforced composite laminates: Part A of the third world-wide failure exercise. J Compos Mater 2013; 47: 2749-2779.

14. Kaddour AS and Hinton MJ. Maturity of 3D failure criteria for fibre-reinforced composites: Comparison between theories and experiments: Part B of WWFE-II. J Compos Mater 2013; 47: 925-966.

15. Kaddour AS and Hinton MJ. Benchmarking of triaxial failure criteria for composite laminates: Comparison between models of 'Part (A)' of 'WWFE-II'. J Compos Mater 2012; 46: 2595-2634.

16. Greif $\mathrm{R}$ and Chapon E. Investigation of successive failure modes in graphite/epoxy laminated composite beams. J Reinf Plast Compos 1993; 12: 602-621.

17. Trochu F, Echaabi J, Pham XT, et al. Theoretical and experimental investigation of failure and damage progression of graphite-epoxy composites in flexural bending test. J Reinf Plast Compos 1996; 15: 740-755.

18. Icardi U, Locatto S and Longo A. Assessment of recent theories for predicting failure of composite laminates. Appl Mech Rev 2007; 60: 76-86.

19. Huybrechts S, Maji A, Lao J, et al. Validation of the quadratic composite failure criteria with out-of-plane shear terms. J Compos Mater 2002; 36: 1879-1887. 
20. El Irhirane, Echaabi H, Aboussaleh JM, et al. Matrix and fibre stiffness degradation of a quasi-isotrope graphite epoxy laminate under flexural bending test. $J$ Reinf Plast Compos 2009; 28: 201-223.

21. Irhirane EH, Abousaleh M, Echaabi J, et al. Modeling and simulation of the failure and stiffness degradation of a graphite epoxy in a three point bending test. $J$ Eng Mater-T ASME 2010; 132: 0310131-0310138.

22. Huang Z-M. Modeling and characterization of bending strength of braided fabric reinforced laminates. J Compos Mater 2002; 36: 2537-2566.

23. Varma IK and Gupta VB. Thermosetting ResinProperties. In: Kelly A and Zweben C (eds) Comprehensive composite materials. Oxford, UK: Elsevier, 2000, pp.1-56.

24. Jones RM. Mechanics of composite materials. 2nd ed. Philadelphia: Taylor \& Francis, 1999.

25. Hyer MW. Stress analysis of fiber reinforced composite materials. Virginia: McGraw Hill, 1998.

26. Davila CG and Camanho PP. Failure criteria for FRP laminates in plane stress. Report NASA, TM-2003212663, 2003.
27. ANSYS Help System, Version 14.5.0, 2014.

28. Tserpes KI, Papanikos P and Kermanidis TH. A three dimensional progressive damage model for bolted joints in composite laminates subjected to tensile loading. Fatigue Fract. Eng. Mater. Struct 2001; 24: 663-675.

29. Hexcel Composites, HexPly 8552 Epoxy Matrix, 2008, http://www.hexcel.com/Resources/DataSheets/PrepregData-Sheets/8552_eu.pdf (accessed February 2015).

30. Lopes CS, Seresta O, Coquet Y, et al. Low-velocity impact damage on dispersed stacking sequence laminates. Part I: Experiments. Compos Sci Technol 2009; 69: 926-936.

31. Mite SR and Kim YK. Process-induced residual stress analysis of AS4/3501-6 composite material. Mech Compos Mater Struct 1998; 5: 153-186.

32. Irvine BT and Ginty CA. Progressive fracture of fiber composites. J Compos Mater 1986; 20: 166-184. 